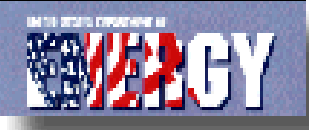

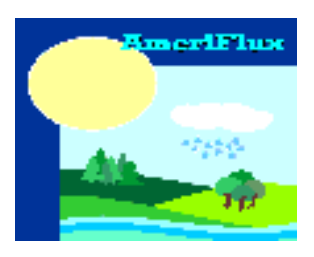

\section{Fiscal Year 2000 Annual Report}
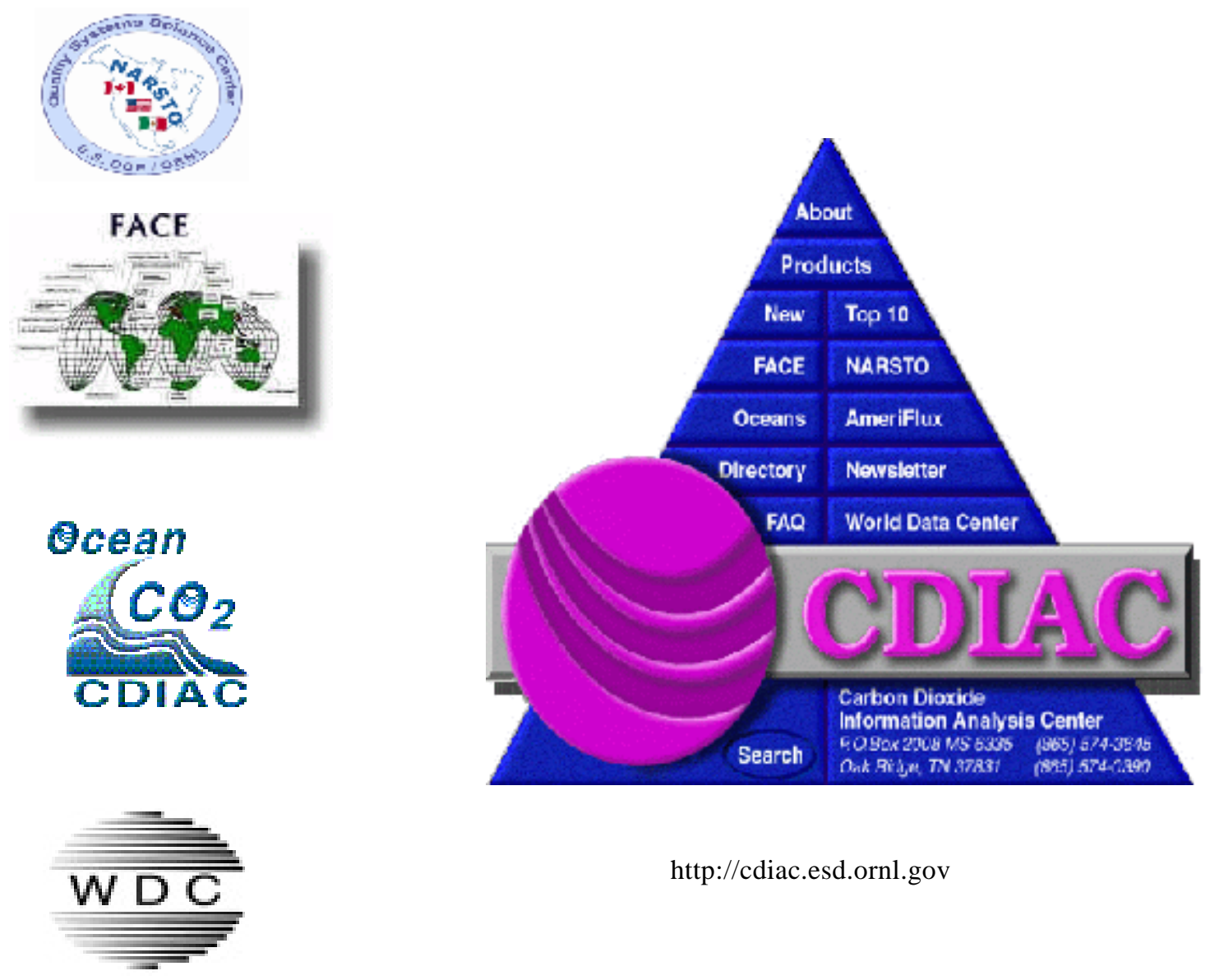

http://cdiac.esd.ornl.gov

Ocean

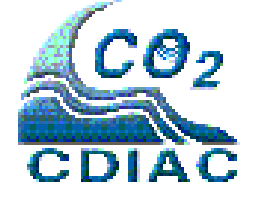

Carbon Dioxide Information Analysis Center World Data Center for Atmospheric Trace Gases

Environmental Sciences Division

Oak Ridge National Laboratory

August 2001 



\section{Carbon Dioxide Information Analysis Center and World Data Center for Atmospheric Trace Gases}

\section{Fiscal Year 2000 Annual Report}

Robert M. Cushman, Thomas A. Boden, Les A. Hook, Sonja B. Jones, Dale P. Kaiser, Alexander Kozyr, ${ }^{*}$ and Tommy R. Nelson

Compiled by Sonja B. Jones and Carolyn R. Householder

*Energy, Environment, and Resources Center

The University of Tennessee

Knoxville, Tennessee

Environmental Sciences Division

August 2001

Prepared for the

Environmental Sciences Division

Office of Biological and Environmental Research

U.S. Department of Energy

Budget Activity Numbers KP1204010, KP1202020, KP1202030

Prepared by the

Carbon Dioxide Information Analysis Center

and World Data Center for Atmospheric Trace Gases

OAK RIDGE NATIONAL LABORATORY

Oak Ridge, Tennessee 37831-6335

managed by

UT-Battelle, LLC

for the

U.S. DEPARTMENT OF ENERGY

under Contract No. DE-AC05-00OR22725 



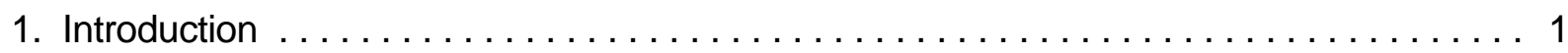

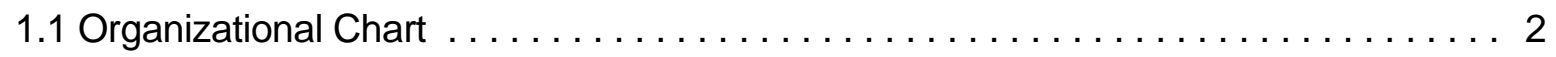

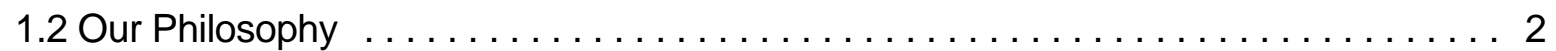

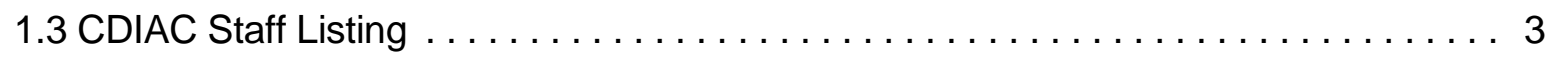

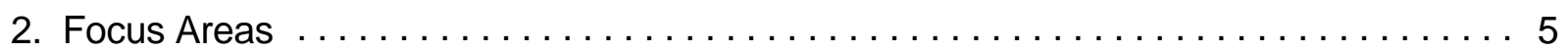

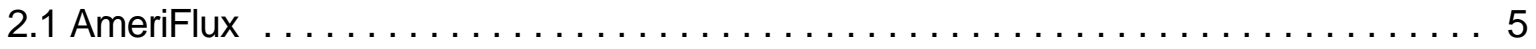

2.1.1 Noteworthy Developments During FY $2000 \ldots \ldots \ldots \ldots \ldots \ldots \ldots$

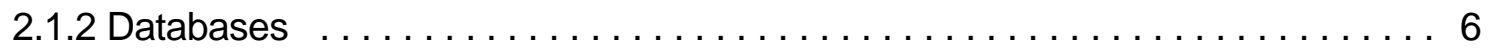

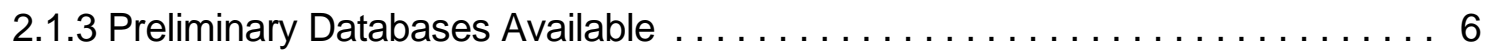

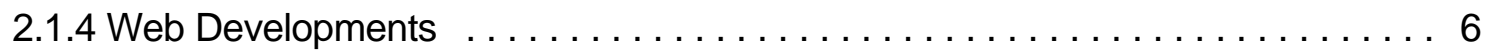

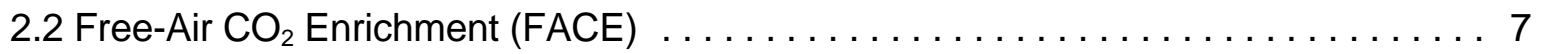

2.3 NARSTO Quality Systems Science Center (QSSC) $\ldots \ldots \ldots \ldots \ldots \ldots \ldots . \ldots 8$

2.3.1 Data Management and Archiving $\ldots \ldots \ldots \ldots \ldots \ldots \ldots \ldots \ldots \ldots \ldots \ldots \ldots \ldots \ldots \ldots$

2.3.2 Data Management Support for Projects . . . . . . . . . . . . . . 9

2.3.3 External Interactions . . . . . . . . . . . . . . . . . . . . 10

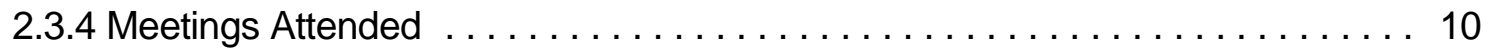

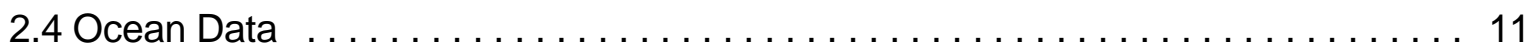

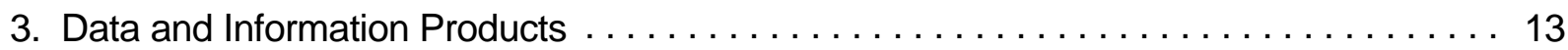

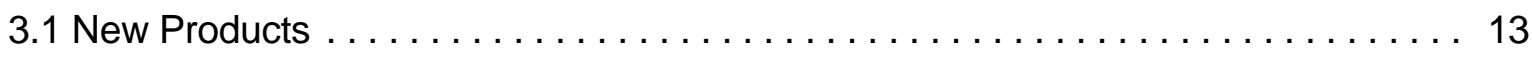

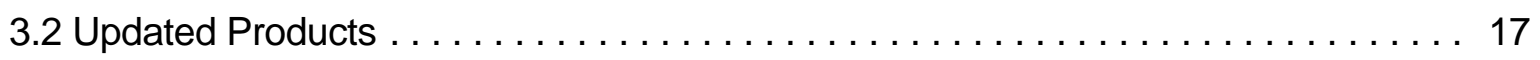

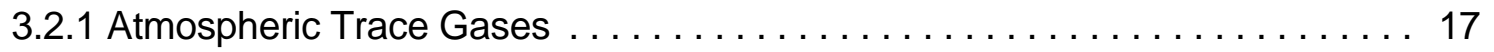

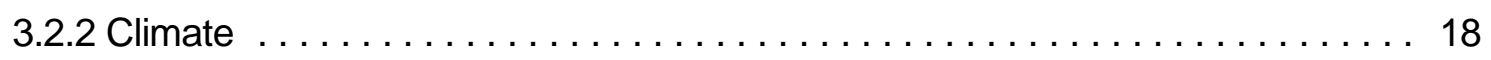

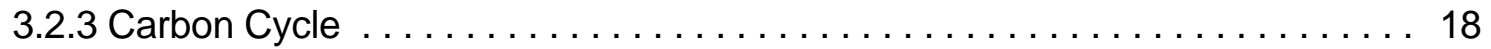

3.3 Trends Online . . . . . . . . . . . . . . . . . . . . . . . . . . 19

3.3.1 Atmospheric Trace Gas Concentrations . . . . . . . . . . . . . . . . . 19

3.3.1.1 Carbon dioxide and carbon isotopes . . . . . . . . . . . . . 19

3.3.2 Greenhouse Gas Emissions . . . . . . . . . . . . . . . . . . 20

3.3.2.1 Carbon dioxide emissions from fossil-fuel consumption . . . . . . . 20

3.3.2.2 Carbon flux from land-cover change $\ldots \ldots \ldots \ldots \ldots \ldots \ldots \ldots \ldots$

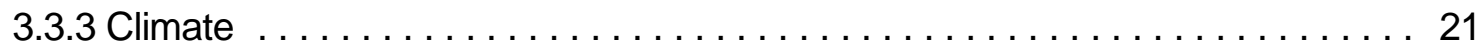

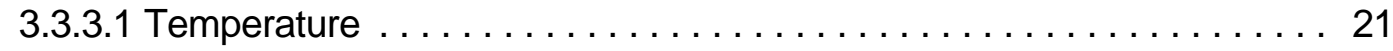

3.4 Newsletters, Reports, and Additional Online Publications . . . . . . . . 23

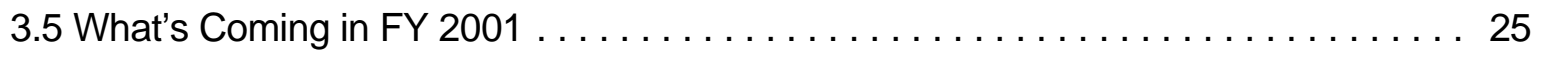

3.5.1 New and Updated Information Products $\ldots \ldots \ldots \ldots \ldots \ldots \ldots \ldots \ldots \ldots$

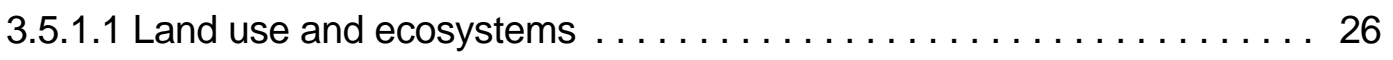

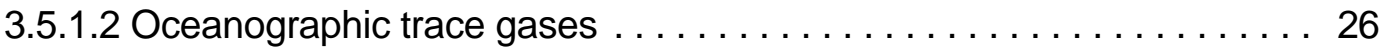

3.5.1.3 Climate . . . . . . . . . . . . . . . . . . . . . . . . 27

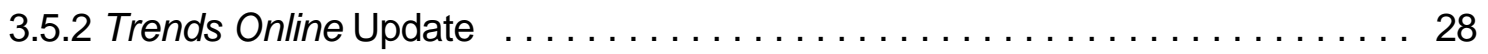




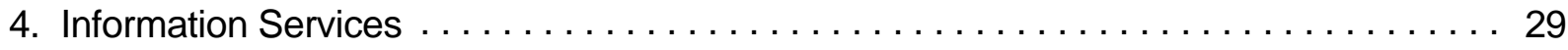

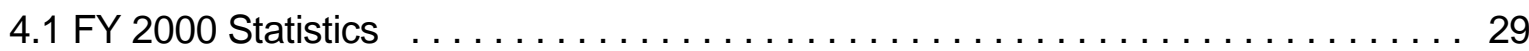

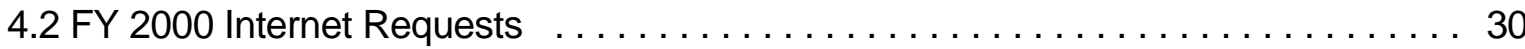

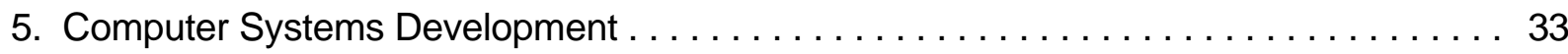

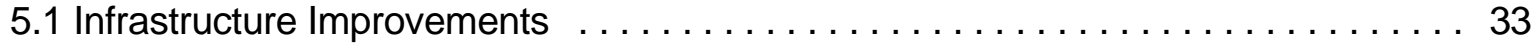

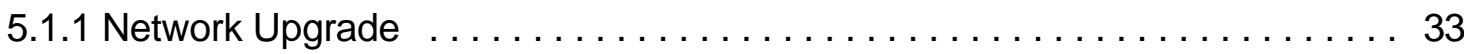

5.1 .2 New Metadata Standard $\ldots \ldots \ldots \ldots \ldots \ldots \ldots \ldots \ldots \ldots \ldots \ldots \ldots$

5.1 .3 New Analysis Software . . . . . . . . . . . . . . . . . . . 33

5.1.4 Desktop Development/Analysis Platform . . . . . . . . . . . . . 34

5.2 Carbon Sequestration Web Server ... . . . . . . . . . . . . . . . . . . 34

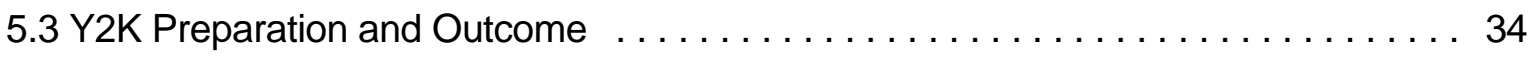

5.4 Computer Systems Maintenance and Updates . . . . . . . . . . . . . . . . . . 34

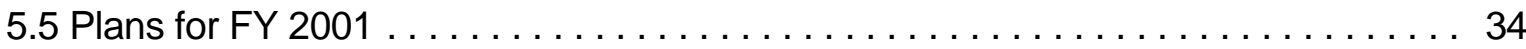

6. CDIAC Presentations, Publications, and Awards $\ldots \ldots \ldots \ldots \ldots \ldots \ldots \ldots \ldots$

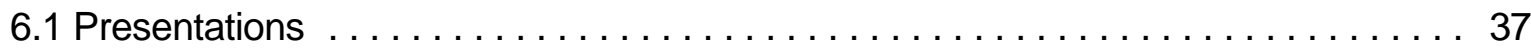

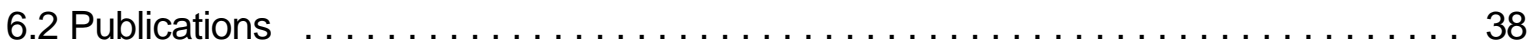

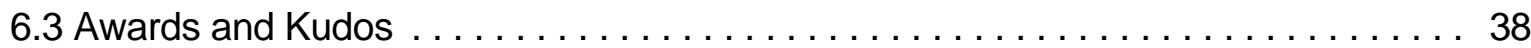

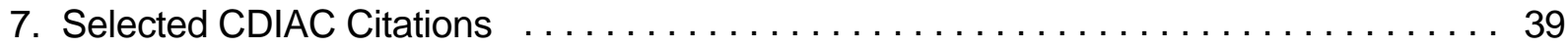

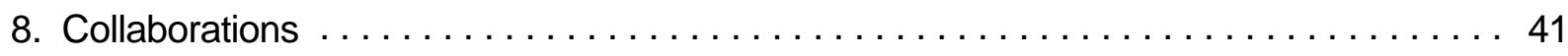

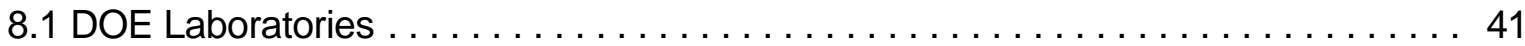

8.2 Other Federal Agencies . . . . . . . . . . . . . . . 41

8.3 Universities/Research Institutions $\ldots \ldots \ldots \ldots \ldots \ldots \ldots \ldots \ldots \ldots \ldots \ldots \ldots$

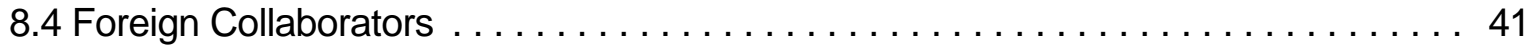

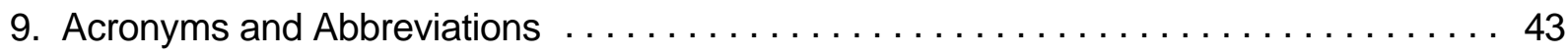




\section{Introduction}

The Carbon Dioxide Information Analysis Center (CDIAC), which includes the World Data Center (WDC) for Atmospheric Trace Gases, is the primary global change data and information analysis center of the U.S. Department of Energy (DOE). More than just an archive of data sets and publications, CDIAC has, since its inception in 1982, enhanced the value of its holdings through intensive quality assurance, documentation, and integration. Whereas many traditional data centers are discipline-based (for example, meteorology or oceanography), CDIAC's scope includes potentially anything and everything that would be of value to users concerned with the greenhouse effect and global climate change, including concentrations of carbon dioxide $\left(\mathrm{CO}_{2}\right)$ and other radiatively active gases in the atmosphere; the role of the terrestrial biosphere and the oceans in the biogeochemical cycles of greenhouse gases; emissions of $\mathrm{CO}_{2}$ and other trace gases to the atmosphere; long-term climate trends; the effects of elevated $\mathrm{CO}_{2}$ on vegetation; and the vulnerability of coastal areas to rising sea levels.

CDIAC is located within the Environmental Sciences Division (ESD) at Oak Ridge National Laboratory (ORNL) in Oak Ridge, Tennessee. CDIAC is co-located with ESD researchers investigating global-change topics, such as the global carbon cycle and the effects of carbon dioxide on climate and vegetation. CDIAC staff are also connected with current ORNL research on related topics, such as renewable energy and supercomputing technologies.

CDIAC is supported by the Environmental Sciences Division (Jerry Elwood, Director) of DOE's Office of Biological and Environmental Research. CDIAC represents DOE in the multi-agency Global Change Data and Information System (GCDIS). Wanda Ferrell is DOE's Program Manager with overall responsibility for CDIAC. Roger Dahlman is responsible for CDIAC's AmeriFlux tasks, and Anna Palmisano for CDIAC's Ocean Data tasks.

CDIAC is comprised of three groups: Data Systems, Information Services, and Computer Systems, with nineteen full-time or part-time staff. The following section provides details on CDIAC's staff and organization.

! The Data Systems Group identifies and obtains databases important to global-change research; analyzes data; compiles needed databases; provides data management support to specific programs (e.g., NARSTO, AmeriFlux, Oceans); and prepares documentation to ensure the longterm utility of CDIAC's data holdings.

! The Information Services Group responds to data and information requests; maintains records of all request activities; analyzes user statistics; assists in Web development and maintenance; and produces CDIAC's newsletter (CDIAC Communications), catalog, glossary, and educational materials.

! The Computer Systems Group provides computer system support for all CDIAC and WDC activities; designs and maintains CDIAC's computing system network; ensures compliance with ORNL/DOE computing security regulations; ensures long-term preservation of CDIAC data holdings through systematic backups; evaluates, develops, and implements software; ensures standards compliance; generates user statistics; provides Web design, development, and oversight; and provides systems analysis and programming assistance for scientific data 
projects.

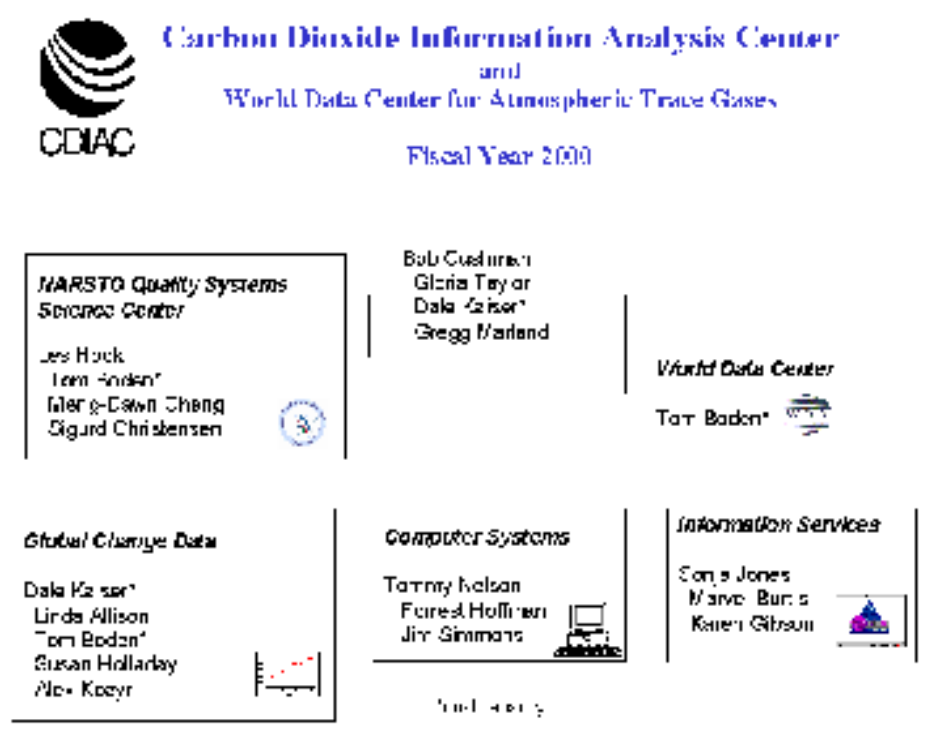

\subsection{Organizational Chart}

\subsection{Our Philosophy}

Our philosophy can be expressed in terms of five interrelated principal objectives:

! Focus on the data and information products that are most in demand by our diverse user community of researchers, educators, students, policymakers, corporate officials, and the interested lay public. These products include the landmark record of rising atmospheric $\mathrm{CO}_{2}$ at Mauna Loa, Hawaii; long-term U.S. global climate data; and global, regional, and national $\mathrm{CO}_{2}$ emissions from fossil-fuel combustion.

! Emphasize data quality, so that our understanding of global climate change is based on reliable information.

! Thoroughly document important databases so that 20 years from now, users (especially those who are not experts in the particular disciplinary area) will be able to understand how a database was produced and what the data mean.

! Provide proper credit to data contributors, so that our users will understand that the data they receive from us originated not with CDIAC but rather with the investigators who so generously chose to share their data with CDIAC.

! Offer data and information to all users without restriction or charge, so that society receives the greatest possible benefit from the originating research programs. Take advantage of current developments in computing technologies for data archival and distribution, so that we provide a secure home for important data and provide the information to our users in the format most appropriate for them. At the same time, CDIAC appreciates that many users still prefer to receive information in 
more traditional formats, and we do our best to accommodate the diversity in the needs of our user community.

\subsection{CDIAC Staff Listing}

\section{CDIAC Staff in FY 2000}

\begin{tabular}{|c|c|c|c|}
\hline Staff & $\begin{array}{c}\text { Phone no. } \\
\text { (Area code 865) }\end{array}$ & $\begin{array}{l}\text { Internet address } \\
\text { (@ornl.gov, unless } \\
\text { stated otherwise) }\end{array}$ & Job title \\
\hline Staff Office & $574-0390$ & cdiac & \\
\hline Linda Allison & & & Numeric data analyst \\
\hline Thomas A. Boden* & $241-4842$ & bodenta & $\begin{array}{l}\text { Director, WDC, Atmospheric } \\
\text { Trace Gases; Ecologist }\end{array}$ \\
\hline Marvel Burtis & & & Editorial Assistant \\
\hline Meng-Dawn Cheng & $241-5918$ & chengmd & NARSTO QSSC chief scientist \\
\hline Sigurd Christensen & $574-7394$ & christensen 1 & NARSTO data analyst \\
\hline Robert M. Cushman & $574-4791$ & cushmanrm & Director, CDIAC \\
\hline Karen Gibson & $241-4854$ & gibsonkn & Co-editor, CDIAC Newsletter \\
\hline Forrest M. Hoffman & $576-7680$ & hoffmanfm & World Wide Web specialist \\
\hline Susan Holladay & & & AmeriFlux data analyst \\
\hline Les A. Hook & $241-4846$ & hookla & NARSTO QSSC Director \\
\hline Sonja B. Jones & $574-3645$ & jonessb1 & $\begin{array}{l}\text { Task leader, Information } \\
\text { Services }\end{array}$ \\
\hline Dale P. Kaiser* & $241-4849$ & kaiserdp & $\begin{array}{l}\text { Meteorologist; } \\
\text { Task Leader, Global Change } \\
\text { Data }\end{array}$ \\
\hline Alexander V. Kozyr ${ }^{a}$ & $576-8449$ & kozyra & Oceanographer \\
\hline Gregg Marland & $241-4850$ & marlandgh & Senior scientist \\
\hline Tommy R. Nelson ${ }^{b}$ & $574-0769$ & nelsontr & $\begin{array}{l}\text { Task leader, Computer } \\
\text { Systems }\end{array}$ \\
\hline James W. Simmons ${ }^{c}$ & $574-1060$ & simmonsjw & Workstation specialist \\
\hline Gloria Taylor & $241-5925$ & taylorgl & Secretary \\
\hline
\end{tabular}

${ }^{a}$ Energy, Environment, and Resources Center, The University of Tennessee, Knoxville

${ }^{b}$ Computational Physics and Engineering Division, ORNL

${ }^{\circ}$ Computing and Telecommunications Services, ORNL

*Dual Capacity 
NOTE: Staff Listing Subject to Change-Please visit the CDIAC Web site for Staff Updates. 


\section{Focus Areas}

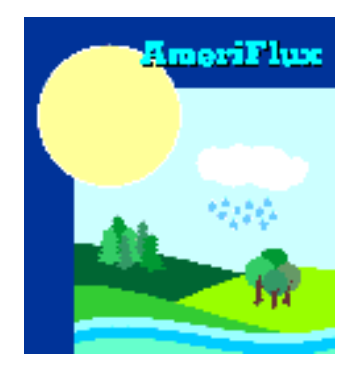

\subsection{Ameriflux}

(http://cdiac.esd.ornl.gov/programs/ameriflux/)

Since 1997, CDIAC has been funded by DOE to provide data management support for the AmeriFlux network. Using the eddy-covariance method, Ameriflux investigators measure the net flux of $\mathrm{CO}_{2}$ to and from major terrestrial ecosystems. The aim of this long-term, continuous monitoring network is to better understand the factors regulating $\mathrm{CO}_{2}$ exchange, including soil processes; vegetation structure, physiology, and stage of succession; and to determine principal feedbacks that affect future states, such as response to changes in climate, air pollution, and $\mathrm{CO}_{2}$ concentrations.

The scientific objectives of AmeriFlux are to establish an infrastructure for guiding, collecting, synthesizing, and disseminating long-term measurements of $\mathrm{CO}_{2}$, water, and energy exchange involving a variety of ecosystems; collect critical new information to help define the current global $\mathrm{CO}_{2}$ budget; enable improved predictions of future concentrations of atmospheric $\mathrm{CO}_{2}$; and enhance understanding of carbon fluxes, net ecosystem production (NEP), and carbon sequestration in the terrestrial biosphere.

The present AmeriFlux network now comprises approximately 45 sites in Brazil, Canada, Costa Rica, and the United States. These sites span a large variety of ecosystems, climate regimes, elevations, and stand ages. For more details on AmeriFlux and related data activities, please visit the AmeriFlux Web site (http://cdiac.esd.ornl.gov/programs/ameriflux/).

The primary responsibilities of the CDIAC AmeriFlux data archive are to continually archive AmeriFlux data; examine contributed AmeriFlux data to ensure quality and consistency; assemble consistent documentation to ensure long-term use of AmeriFlux data; compile ancillary information for each AmeriFlux site [e.g., leaf area index (LAI), land-use histories] for the purpose of creating network-wide databases; and creating and maintaining the AmeriFlux Web site.

The AmeriFlux data archive at CDIAC offers two types of data: preliminary and final. Preliminary data are contributed by AmeriFlux principal investigators (PIs). The file formats and contents are unchanged from their original submission state. Any descriptive files provided are those furnished by the site Pls. The values provided in these preliminary files have been scrutinized by the Pls but are subject to change. Preliminary AmeriFlux data are generously contributed to CDIAC and made available in order to make AmeriFlux data available as quickly as possible. Preliminary AmeriFlux data sent to CDIAC are checked, processed into a consistent data format, and documented by CDIAC before release as a final data set. All data issues investigated by CDIAC are resolved with the contributing Pls, and no values are changed without the approval of the contributing PIs.

\subsubsection{Noteworthy Developments During FY 2000}


! The CDIAC AmeriFlux archive was designated as the hub for an FY 2000 validation exercise. Micrometeorological flux measurements from AmeriFlux sites will be used, along with gross primary production (GPP) estimates obtained from the moderate-resolution imaging spectroradiometer (MODIS) sensor launched December 1999 on the National Aeronautics and Space Administration (NASA) Terra satellite, in the global biome model-biogeochemical cycle (BIOMEBGC) model, and other models, to calculate GPP, NEP, and Net Primary Production (NPP). The model-calculated GPP, NEP, and net primary production (NPP) estimates will then be compared with the same estimates derived from measurements at the individual AmeriFlux sites.

\subsubsection{Databases}

! Metolius Natural Research Area for Central Oregon (old-growth ponderosa pine), 1996-1997, data posted October 17, 1999

! Ponca City, Oklahoma (agricultural crops, wheat), 1996-1997, data posted February 24, 2000

! Shidler, Oklahoma (tallgrass prairie), 1996-1997, data posted February 24, 2000

! Walker Branch Watershed, Oak Ridge National Laboratory, Tennessee (deciduous forest), 1995-1998, data posted March 16, 2000

\subsubsection{Preliminary Databases Available}

! Atqasuk, Alaska (moist-wet coastal sedge tundra and moist-tussock tundra), 1999

! Barrow, Alaska (moist-wet coastal sedge tundra), 1998-1999

! Happy Valley, Alaska (moist, acidic tundra), 1994-1995

! U-Pad, Alaska (Moist, wet sedge tundra), 1994-1995

! Blodgett Forest, California (young ponderosa pine), 1997-1998

! Sky Oaks Biological Field Station, California [chaparral, unmanaged old (78 years) and young (4 years) sites], 1997-2000

! University of Florida, Gainesville, Florida [slash pine, 24-year old stand, mid-rotation stand, and a recently clear-cut (3 year-old) stand], 1998-2000

! Niwot Ridge, Colorado (subalpine forest), 1998-2000

! Bondville, Illinois (agricultural crops, alternating corn and soybeans), 1996-2000

! Howland Forest, Maine (boreal, northern hardwood forest), 1996-1999

! Harvard Forest, Massachusetts (mixed deciduous forest), 1991-2000 (EC) fluxes and meteorological data; 1992-1995 hydrocarbon measurements; and 1990-1996 trace gas profiles

! Duke Forest, North Carolina (loblolly pine forest), 1997-2000

! Little Washita, Oklahoma (rangeland), 1997-1999

! Fort Peck, Montana (grassland), 1999

! Wind River Crane Site, Washington (old-growth Douglas fir forest), 1998 fluxes and met data

! Park Falls, Wisconsin (lowland-wetland forest), 1997-2000

! Willow Springs Ecosystem Processes Site, Wisconsin (upland hardwood forest), 1998-2000 


\subsubsection{Web Developments}

! Updated the list of AmeriFlux measurement parameters, standard definitions, and preferred reporting formats and maintained the lists of AmeriFlux sites and participants.

\subsection{Free-Air $\mathrm{CO}_{2}$ Enrichment (FACE)}

\section{(http://cdiac.esd.ornl.gov/programs/FACE/face.html)}

Free-Air $\mathrm{CO}_{2}$ Enrichment (FACE) technology provides a means by which the environment around growing plants may be modified

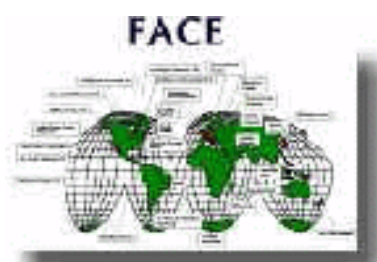
to realistically simulate future concentrations of atmospheric $\mathrm{CO}_{2}$. Unlike growth chambers and greenhouses, no containment is required with FACE designs. Previously difficult-to-study natural conditions, such as temperature, precipitation, pollination, wind, humidity, and sunlight, are now possible. In addition, the FACE program reduces or eliminates plant size or growth problems caused by the constraint of enclosures (although the system must be sized, or expandable, to accommodate the anticipated future size of the plants during the lifetime of the experiment). Therefore, long-term studies may be conducted. FACE field data represent plant and ecosystem responses to concentrations of atmospheric $\mathrm{CO}_{2}$ in a natural setting possible during the next century.

FACE research technology creates a platform for multidisciplinary, ecosystem-scale research on the effects of elevated atmospheric $\mathrm{CO}_{2}$ concentrations over extended periods of time. In doing so, a large amount and variety of high- $\mathrm{CO}_{2}$-grown plant material can be produced to support the research of many cooperating scientists. This would encourage research by teams of investigators, who can study different aspects of an ecosystem's response to $\mathrm{CO}_{2}$ enrichment. This concurrent use by numerous independent scientists provides economies of scale and the potential to gain new insights into ecosystem responses that are difficult or impossible to obtain with smaller scale, enclosed, studies.

CDIAC continued to develop its FACE Web site (http://cdiac.esd.ornl.gov/programs/FACE/ face.html) to support the global network of approximately thirty research sites that are operational, in development, or proposed. During FY 2000, CDIAC updated the links to, and information about, the research sites; updated the list of FACE-related publications; and provided links to news items of interest to the FACE community (including stories concerning the latest FACE research results). Bob Cushman attended the FACE 2000 conference in Tsukuba, Japan, and discussed data and information management with investigators from the various FACE sites. 


\subsection{NARSTO Quality Systems Science Center (QSSC)}

(http://cdiac.esd.ornl.gov/programs/NARSTO/narsto.html)

The tri-national (Canada, United States, and Mexico) NARSTO program (formerly the North American Research Strategy for Tropospheric Ozone) has broadened its objectives to include atmospheric pollutants

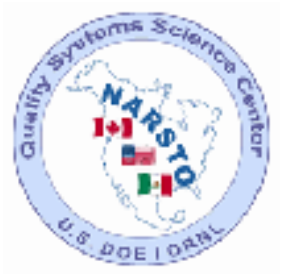
besides ozone. NARSTO is a nonbinding public/private alliance, open to science agencies, regulatory agencies, regulated industries, academic institutions, environmentalists, and public interest groups in North America. Its primary mission is to coordinate and enhance policy-relevant scientific research, assessment, and modeling of tropospheric pollution behavior, with the central programmatic goal of determining workable, efficient, and effective strategies for local and regional air-pollution management.

In January 1997, DOE's Environmental Sciences Division began their sponsorship of the NARSTO Quality Systems Science Center (QSSC) within CDIAC. The QSSC reports to the NARSTO Executive Steering Committee through the NARSTO Management Coordinator and collaborates with the Science Teams.

The QSSC works to ensure that relevant quality management systems are planned and implemented by NARSTO technical programs. The NARSTO Quality Systems Management Plan (QSMP) (http://cdiac.esd.ornl.gov/programs/NARSTO/pdf/qsmp_current_version.PDF) and the Quality Planning Handbook (QPHB) (http://cdiac.esd.ornl.gov/programs/NARSTO/pdf/qphb_ current_version.PDF), developed and maintained by the QSSC, provide the framework within which all quality-related activities are conducted.

The QSSC reviews project management and fieldwork planning documents and provides information to NARSTO partners seeking assistance with quality assurance, quality control, data management, and data archival. The QSSC plans and coordinates NARSTO data management, data archival, and data dissemination activities. Timely sharing of, and access to, quality-assured NARSTO data and research products (e.g., computer models, methods, procedures, and reports) by the scientific community is essential to the success of the NARSTO program. The QSSC developed and maintains the NARSTO Data Management Handbook (DMHB) ( http://cdiac.esd.ornl. gov/programs/NARSTO/pdf/dmhb_current_version.PDF) that contains data format conventions, data validation guidance, and data archive transfer format specifications. The QSSC performs a final quality assurance check of data sets submitted for archival, prepares archive documentation, and coordinates their transfer to the publicly available NARSTO permanent data archive (PDA) at the NASA Langley Distributed Active Archive Center (DAAC). Data are online at $h$ ttp://eosweb.larc. nasa.gov/.

NARSTO quality systems and data management documents are available online at $h t t p: / / c d i a c . e s d$. ornl.gov/programs/NARSTO/.

In addition to these quality and data management activities, the QSSC continues to develop the NARSTO Measurement Methods Compendium Web site for ozone and particulate matter sampling and analysis technologies and methodologies. Method descriptions are available online at 
http://narsto.esd.ornl.gov/Compendium/.

QSSC staff expertise includes atmospheric chemistry, quality systems management, environmental data quality management, and data management coordination.

The FY 2000 QSSC's activities fall into three general areas: data management and archiving, data management support for projects, and external interactions.

\subsubsection{Data Management and Archiving}

The QSSC implemented The NARSTO Data and Information Sharing Tool (DIST). DIST is a Webbased index and clearinghouse of atmospheric measurement, chemistry data, and metadata. It can be used by a small group of investigators to securely share project data before the data are generally available, as well as allow the larger research community to locate and access data from numerous data sources in the public domain. The data in the NARSTO DIST includes results from NARSTO studies and non-NARSTO studies with data of interest to the atmospheric research community. Data are indexed using consistent metadata categories to support searching by project, location, date, keyword, investigator, etc. Projects and investigators with relevant data products (e.g., measurement data, model outputs, images, etc.) are invited to participate. Data providers can use the Web-based DIST to conveniently enter metadata and to link their data and documents into the searchable DIST index. A File Transfer Protocol (FTP) site is now associated with DIST for storage and retrieval of data sets. DIST is a key component in the flow of data from projects to the NARSTO PDA with output capabilities that facilitate metadata and data archiving.

\subsubsection{Data Management Support for Projects}

The QSSC provides assistance to NARSTO research managers, principal investigators, and data managers. A good example of this is our work with the Central California Air Quality Study database managers.

The QSSC is also providing data management support to the U.S. Environmental Protection Agency (EPA) Particulate Matter (PM) Supersites Program. In consultation with EPA and the Data Coordinators of the Supersite projects, the QSSC, with the financial support of EPA, is coordinating the following activities:

1. Support for development and maintenance of a consistent set of metadata for the Supersites measurement data. Metadata are the data that describe, for measured results, the important details as to: what, where, when, how, why, and by whom. Several working groups were initially established to develop consensus on formats for site names, variable names, units, methods, and flags. Weekly teleconference discussions keep the process moving. The Supersites Program will be providing quality-assured data to the QSSC for archiving in accordance with the published NARSTO guidelines.

2. Implementation of the NARSTO DIST for the Supersites Program to support sharing of data among investigators and to use DIST's output capabilities to facilitate data archiving. The addition of new features and modifications to metadata will be made as necessary for effective 
implementation. The addition of new DIST users, system administration, and user support is included in this support.

3. Implementation of a Supersites FTP Site to support the sharing of data using DIST among Supersites Program participants. Supersite project data coordinators may add and maintain data on the FTP site to allow program-wide access to data, while not permitting access to secure project systems.

To address these activities in a coordinated and efficient manner, the QSSC and the Supersites working groups are utilizing the considerable technical, measurement, and data management knowledge and system resources that already exist across the Supersites projects, NARSTO, EPA, and externally. Other NARSTO, EPA, and similar atmospheric research projects are encouraged to take advantage of these results and contribute their experience and data. This coordinated effort, envisioned as a model for future cooperation, is a prime example of why NARSTO was formed and how it can function.

\subsubsection{External Interactions}

QSSC promotes coordination of NARSTO Data Exchange standards and automated processing programs with Bill Sukloff of the Atmospheric Environment Service (AES) of Canada. We continue to utilize existing resources (people and software) to the benefit of both programs. The QSSC cosponsored a 10-day visit by Bill Sukloff for this purpose.

\subsubsection{Meetings Attended}

Les Hook, Director of the NARSTO QSSC, attended the Joint Annual Meeting of the NARSTO Executive Assembly and Executive Steering Committee, March 8-9, 2000, at the White House Conference Center, in Washington, D.C. He presented a report entitled "NARSTO Quality Systems and Data Management Activities". The report summarized QSSC responsibilities and activities for the past year, previewed planned activities, and described the recently implemented NARSTO DIST that will be used by NARSTO Technical Programs.

Les Hook and Meng-Dawn Cheng represented NARSTO's QSSC at the NARSTO 2000 meeting "Tropospheric Aerosols Science and Decisions in an International Community" held in Queretaro, Mexico. Les co-chaired the Data Management/Quality session, presented "The NARSTOData and Information Sharing Tool", and displayed a poster, "The Truth about Data Management" (both the presentation and poster were co-authored with Sigurd Christensen). Meng-Dawn presented "RealTime Emission Measurement of Fine Particulates and Heavy Metals" (co-authored with Madhavi Martin and Thomas Wainman, also of the ORNL Environmental Sciences Division) in the session on Stationary Sources/Controls.

\subsection{Ocean Data}

(http://cdiac.esd.ornl.gov/oceans/home.html)

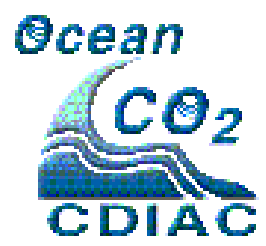


The World Ocean Circulation Experiment (WOCE) Hydrographic Program (WHP) is a major component of the World Climate Research Program with the overall goal of better understanding the ocean's role in climate and climatic changes resulting from both natural and anthropogenic causes. The levels of $\mathrm{CO}_{2}$ in the oceans are unevenly distributed because of complex circulation patterns and biogeochemical cycles. Although $\mathrm{CO}_{2}$ is not an official WOCE measurement, a coordinated effort, supported in the U.S. by DOE, was made on WOCE cruises through 1998 to measure the global-scale and temporal distributions of total carbon dioxide $\left(\mathrm{TCO}_{2}\right)$ and related parameters.

Goals of the survey were to estimate the meridional transport of inorganic carbon in a manner analogous to the estimation of the transport of oceanic heat and to build a database suitable for carbon cycle modeling and the estimation of anthropogenic $\mathrm{CO}_{2}$ increase in the oceans. The $\mathrm{CO}_{2}$ survey took advantage of the sampling opportunities provided by the WHP cruises during this period. The final data set is expected to cover approximately 23,000 stations from 42 WOCE cruises.

CDIAC provides data management support for the Joint Global Ocean Flux Study (JGOFS) $\mathrm{CO}_{2}$ measurements taken aboard research vessels during WHP cruises. DOE sponsored $\mathrm{CO}_{2}$ measurement operations and continues to sponsor CDIAC's data support activities, which include data archival, data checking and evaluation, preparation of data documentation, and data dissemination. All $\mathrm{CO}_{2}$-related data are checked before documentation and distribution. Through the end of $\mathrm{FY} 2000$, DOE-supported investigators had collected $\mathrm{CO}_{2}$ measurements on 42 WOCE cruises. CDIAC has received data from 40 of these cruises, and 35 of these data sets have undergone quality assurance checks with 17 fully documented as numeric data products (NDPs).

CDIAC provides data management support for the GLobal Ocean Data Analysis Project (GLODAP). GLODAP is a cooperative effort of investigators funded for synthesis and modeling projects through the National Oceanic and Atmospheric Administration (NOAA), DOE, and the National Science Foundation (NSF). Cruises conducted as part of the WOCE, JGOFS, and the NOAA Ocean-Atmosphere Carbon Exchange Study (OACES) over the decade of the 90's have generated oceanographic data of unparalleled quality and quantity.

Most of the data have been reported to national archive facilities but have not been integrated into an internally consistent global data set. GLODAP will compile that data set and examine the global distribution and inventories of oxygen, nutrients, natural and anthropogenic carbon species, natural and bomb-produced radiocarbon, and ${ }^{13} \mathrm{C}$. These estimates will be used to infer nutrient remineralization ratios (Redfield ratios) and the rate of anthropogenic $\mathrm{CO}_{2},{ }^{13} \mathrm{C}$, and bomb ${ }^{14} \mathrm{C}$ uptake in the oceans. These estimates provide an important benchmark for comparison with future observational studies. They also provide tools for the direct evaluation of numerical ocean carbon models.

CDIAC provides data management support for the project CARINA (CARbon dioxide In the North Atlantic ocean) which emerged from a workshop on " $\mathrm{CO}_{2}$ in the northern North Atlantic," held June 1999 in Delmenhorst, Germany. 
The CARINA objectives are:

! to bring together research groups that measure $\mathrm{CO}_{2}$ in the North Atlantic Ocean;

! to create an inventory of $\mathrm{CO}_{2}$ measurements carried out in the North Atlantic Ocean;

! to make available unpublished data to the data contributors (data access);

! to form working groups that cooperate on various aspects of the $\mathrm{CO}_{2}$ system in the North Atlantic; and

! to exchange information concerning $\mathrm{CO}_{2}$ research in the North Atlantic.

CDIAC also plays a major role in the $\mathrm{CO}_{2}$ data management for the North Pacific Marine Science Organization (PICES) Working Group 13 (WG-13). The main goal of the WG-13 is to work with the data centers [Japan Oceanographic Data Center (JODC), National Oceanographic Data Center (NODC), CDIAC, Marine Environmental Data Service (MEDS), et al.] to complete an International North Pacific data set for $\mathrm{CO}_{2}$ and $\mathrm{CO}_{2}$-related parameters and to encourage PICES countries (Japan, South Korea, China, Canada, Russia, and United States) and non-PICES countries to contribute data and information on data to the PICES data inventory. 


\section{Data and Information Products}

CDIAC's carbon dioxide-related products provide data and information in several areas relevant to the greenhouse effect and global climate change. These areas include records of the concentration of $\mathrm{CO}_{2}$ and other radiatively active gases in the atmosphere, the role of the terrestrial biosphere and the oceans in the biogeochemical cycles of greenhouse gases, emissions of $\mathrm{CO}_{2}$ to the atmosphere, long-term climate trends, the effects of elevated $\mathrm{CO}_{2}$ on vegetation, and the vulnerability of coastal areas to rising sea level.

CDIAC packages and releases holdings in the form of data products [e.g., numeric data packages (NDPs), databases (DBs), and a computer model package (CMP)] and printed publications. All products are provided free of charge and are available while supplies last. Data files and documentation (text or HTML version), which accompany the data products, may be accessed and downloaded from CDIAC's Web site ( $h$ ttp://cdiac.esd.ornl.gov), from CDIAC's anonymous FTP (file transfer protocol) area (ftp://cdiac.esd.ornl.gov), or requested directly from CDIAC on various types of media (e.g., CD-ROM, floppy diskette). Printed reports are available from CDIAC on request. All technical questions (e.g., methodology or accuracy) should be directed to the CDIAC staff member who is responsible for preparing the individual data products.

During FY 2000, CDIAC published four new NDPs, one CDIAC publication, and one database under the auspices of DOE. CDIAC updated three NDPs and one database. CDIAC also added two new records to Trends Online (http://cdiac. esd.ornl.gov/trends/trends. $h t m$ ) and updated five existing records.

\subsection{New Products}

Vegetation Response of $\mathrm{CO}_{2}$ and Climate, A Database of Herbaceous Vegetation Responses to Elevated Atmospheric $\mathrm{CO}_{2}$

Contributed by Jones, M. H., and P. S. Curtis, Department of Evolution, Ecology, and Organismal Biology, The Ohio State University, Columbus, Ohio

Prepared by Robert M. Cushman and Antoinette L. Brenkert, CDIAC

NDP-073 (published: November 1999)

(http://cdiac.esd.ornl.gov/epubs/ndp/ndp073/ndp073.html)

This database, which accompanies the database NDP-072, A Data Base of Woody Vegetation Responses to Elevated Atmospheric $\mathrm{CO}_{2}$, was compiled from the published literature for 121 independent $\mathrm{CO}_{2}$-enrichment studies and is used to support a meta-analysis of research results on the response by herbaceous vegetation to increased atmospheric $\mathrm{CO}_{2}$ levels.

Seventy-eight independent $\mathrm{CO}_{2}$-enrichment studies, covering 53 species and 26 response parameters, reported mean response, sample size, and variance of the response. An additional 43 studies, covering 25 species and six response parameters, did not report variances. 
This data base may also be used to explore the effects of environmental factors (e.g., nutrient levels, light intensity, temperature), stress treatments (e.g., drought, heat, ozone), and effects of experimental conditions (e.g., duration of $\mathrm{CO}_{2}$ exposure, pot size, type of $\mathrm{CO}_{2}$ exposure facility) on plant responses to elevated $\mathrm{CO}_{2}$ levels.

Carbon Dioxide, Hydrographic, and Chemical Data Obtained During the $R / V$ Hespérides Cruise in the Atlantic Ocean (WOCE Section A5, July 14-August 15, 1992)

Contributed by Millero, F. J., S. Fiol, and D. M. Campbell, Rosenstiel School of Marine and Atmospheric Science, University of Miami, Florida; and G. Parrilla, Instituto Español de Oceanografía, Madrid, Spain

Prepared by Alexander Kozyr and Linda J. Allison, CDIAC

NDP-074 (published: June 2000)

(http://cdiac.esd.ornl.gov/oceans/ndp_074/ndp074.html)

This data documentation discusses the procedures and methods used to measure total carbon dioxide $\left(\mathrm{TCO}_{2}\right)$, total alkalinity (TALK), and $\mathrm{pH}$ at hydrographic stations during the $\mathrm{R} / \mathrm{V}$ Hespérides oceanographic cruise in the Atlantic Ocean (Section A5). Conducted as part of the World Ocean Circulation Experiment (WOCE), the cruise began in Cadiz, Spain, on July 14, 1992, and ended in Miami, Florida, on August 15, 1992. Measurements made along WOCE Section A5 included conductivity, temperature, and depth (CTD) pressure; temperature; salinity; oxygen; bottle salinity; oxygen; phosphate; nitrate; nitrite; silicate; $\mathrm{TCO}_{2}$; TALK; and pH.

Carbon Dioxide Hydrographic, and Chemical Data Obtained During the $R / V$ John V. Vickers Cruise in the Pacific Ocean (WOCE Section P13, NOAA CGC92 Cruise, August 4-October 21, 1992)

Contributed by Dickson, A. G., C. D. Keeling, and P. R. Guenther, Scripps Institution of Oceanography (SIO), University of California, San Diego, California, and J. L. Bullister, Pacific Marine Environmental Laboratory, NOAA, Seattle, Washington

Prepared by Alexander Kozyr, CDIAC

NDP-075 (published: December 2000)

(http://cdiac.esd.ornl.gov/oceans/ndp_075/ndp075.htm)

This data documentation discusses the procedures and methods used to measure total carbon dioxide $\left(\mathrm{TCO}_{2}\right)$ and total alkalinity (TALK) at hydrographic stations during the R/V John V. Vickers oceanographic cruise in the Pacific Ocean (Section P13). Conducted as part of the World Ocean Circulation Experiment (WOCE) and the National Oceanic and Atmospheric Administration's Climate and Global Change Program, the cruise began in Los Angeles, California, on August 4, 1992, with a transit line (Leg 0) to Dutch Harbor, Alaska. On August 16, 
the ship departed Dutch Harbor on Leg 1 of WOCE section P13. On September 15, the R/V John V. Vickers arrived in Kwajalein, Marshall Islands, for emergency repairs, and after 11 days in port departed for Leg 2 of Section P13 on September 26. The cruise ended on October 21 in Noumea, New Caledonia. Measurements made along WOCE Section P13 included pressure, temperature, salinity [measured by a conductivity, temperature, and depth sensor (CTD)], bottle salinity, bottle oxygen, phosphate, nitrate, nitrite, silicate, chlorofluorocarbons (CFC-11, CFC-12), $\mathrm{TCO}_{2}$, and TALK.

\section{Global Distribution of Total Inorganic Carbon and Total Alkalinity Below the Deepest Winter Mixed Layer Depths}

Contributed by Goyet, C., and R. J. Healy, Woods Hole Oceanographic Institution, Woods Hole, Massachusetts, and J. P. Ryan, Monterey Bay Aquarium Research Institute, Moss Landing, California

Prepared by Alexander Kozyr, CDIAC

NDP-076 (published: May 2000)

(http://cdiac.esd.ornl.gov/oceans/ndp_076/ndp076.html)

Modeling the global ocean-atmosphere carbon dioxide system is becoming increasingly important to greenhouse gas policy. These models require initialization with realistic three-dimensional (3-D) oceanic carbon fields. This report presents an approach to establishing these initial conditions from an extensive global database of ocean $\mathrm{CO}_{2}$ system measurements and well-developed interpolation methods. These methods are limited to waters below the deepest mixed layer. The data used for these interpolations include the recent high-quality data sets from the World Ocean Circulation Experiment (WOCE), Joint Global Ocean Flux Study (JGOFS), and Ocean-Atmosphere Carbon Exchange Study (OACES) programs. Prior to analysis, all carbon data were adjusted to established reference material listed in http://www-mpl.ucsd.edu/people/adickson/ $\mathrm{CO}_{2} \mathrm{QC} /$. The interpolation methodology employs correlation between $\mathrm{CO}_{2}$ system properties and other more widely measured properties: potential temperature, salinity, and apparent oxygen utilization. The correlations are computed for each profile, and the coefficients are interpolated to the $1 \mathrm{E} \times 1 \mathrm{E} \times 32$ vertical-layer grid at a monthly temporal resolution. Finally, the gridded coefficients are applied to a global monthly climatology of ocean temperature, salinity, and oxygen to compute total $\mathrm{CO}_{2}\left(\mathrm{TCO}_{2}\right)$ and total alkalinity (TALK) for the 3-D grid.

This approach offers advantages over spin up of a single profile in defining spatial variation in $\mathrm{CO}_{2}$ system properties because it reduces initialization time and provides a more accurate carbon field. The results provide an unprecedented "view" of the global distribution of TALK and $\mathrm{TCO}_{2}$ in the ocean. These results as well as those from the monthly mixed layer depths can be used in diagnostic and prognostic global ocean models.

The interpolated data set includes seasonal $\mathrm{TCO}_{2}$ and TALK fields as well as the coefficients used to estimate these concentrations and the monthly mixed layer depths. 


\section{Comparison of the Carbon System Parameters at the Global $\mathrm{CO}_{2}$ Survey Crossover Locations in the North and South Pacific Ocean, 1990-1996}

Contributed by Feely, R. A., M. F. Lamb, and D. J. Greeley, NOAA, Pacific Marine Environmental Laboratory (PMEL), Seattle, Washington; and R. Wanninkhof, NOAA, Atlantic Oceanographic and Meteorological Laboratory, Miami, Florida

Prepared by Linda Allison and Dana Griffith, CDIAC

ORNL/CDIAC-115

(published: December 1999)

(http://cdiac.esd.ornl.gov/oceans/pmel/pmel.html)

As a collaborative program to measure global ocean carbon inventories and provide estimates of the anthropogenic $\mathrm{CO}_{2}$ uptake by the oceans, NOAA and DOE have sponsored the collection of ocean carbon measurements as part of the WOCE OACES cruises. The cruises discussed here occurred in the North and South Pacific from 1990 through 1996. The carbon parameters from these 30 crossover locations have been compared to ensure that a consistent global data set emerges from the survey cruises. The results indicate that for dissolved inorganic carbon, fugacity of $\mathrm{CO}_{2}$, and $\mathrm{pH}$, the agreements at most crossover locations are well within the design specifications for the global $\mathrm{CO}_{2}$ survey; whereas, in the case of total alkalinity, the agreement between crossover locations is not as close.

\section{Atmospheric Methyl Chloride}

Contributed by Khali, M. A. K., Department of Physics, Portland State University, Portland, Oregon; and R. A. Rasmussen, Department of Environmental Science and Engineering, Oregon Graduate Institute, Portland, Oregon

Prepared by Thomas A. Boden, CDIAC

(added: February 2000)

(http://cdiac.esd.ornl.gov/epubs/other/methylchl.html)

Monthly average concentrations of atmospheric methyl chloride from seven locations representing the polar, middle, and tropical latitudes, and both hemispheres are provided in this database. The seven primary sites include Pt. Barrow, Alaska; Cape Kumukahi and Mauna Loa, Hawaii; Cape Matatula, Samoa; Cape Grim, Tasmania; and the South Pole and Palmer Station, Antarctica. Concentration measurements from these seven sites cover a period of 16 years (1981-1997). Monthly data, including vertical distributions at 20 short-term sites from various latitudes, were also measured between 1987-1989.

Air samples were collected in stainless steel flasks, and methyl chloride concentrations were measured using an Electron Capture Gas Chromatograph. Concentrations are reported as 
mixing ratios in dry air. The concentrations are determined by using a set of calibration standards that are referenced against a primary standard that is also used to establish the absolute concentration. The primary standards were prepared by the investigators in the absence of an available standard from a centralized location.

These data are useful for: (1) global methyl chloride budget analyses, (2) determining the atmospheric distribution and trends of methyl chloride, and (3) estimating the total emissions at various latitudes.

\subsection{Updated Products}

\subsubsection{Atmospheric Trace Gases}

\section{Atmospheric $\mathrm{CO}_{2}$ Concentrations-Mauna Loa Observatory, Hawaii, 1958-1999}

Contributed by Keeling, C. D., and T. P. Whorf, Scripps Institution of Oceanography (SIO) at the University of California, San Diego, California

Prepared by Thomas A. Boden, CDIAC

NDP-001 (updated: August 2000)

(http://cdiac.esd.ornl.gov/ndps/ndp001.html)

The Mauna Loa atmospheric $\mathrm{CO}_{2}$ measurements, which began in 1958, constitute the longest continuous record of atmospheric $\mathrm{CO}_{2}$ concentrations available in the world. The Mauna Loa site is considered one of the most favorable locations for measuring undisturbed air because possible local influences of vegetation or human activities on atmospheric $\mathrm{CO}_{2}$ concentrations are minimal, and any influences from volcanic vents may be excluded from the records. The methods and equipment used to obtain these measurements have remained essentially unchanged during the 40-year monitoring program.

The Mauna Loa record shows a $16.6 \%$ increase in the mean annual concentration, from 315.83 parts per million by volume (ppmv) of dry air in 1959 to $368.37 \mathrm{ppmv}$ in 1999. The $2.9 \mathrm{ppmv}$ increase in mean annual concentration from 1997 to 1998 represents the largest single yearly jump since the Mauna Loa record began in 1958; the 1998-1999 increase in mean annual concentration was $1.67 \mathrm{ppmv}$.

\section{The ALE/GAGE/AGAGE Network}

Contributed by Prinn, R., Massachusetts Institute of Technology (MIT); D. Cunnold, F. Alyea, R. Wang, and D. Hartley, Georgia Institute of Technology; P. Fraser and L. Paul Steele, Commonwealth Scientific and Industrial Research Organisation (CSIRO); R. Weiss, Scripps Institution of Oceanography (SIO); and P. Simmonds, International Science Consultants 
Prepared by Thomas A. Boden, CDIAC

DB-001 (revised: August 2000)

(http://cdiac.esd.ornl.gov/ndps/alegage.html)

This network provides continuous high-frequency measurements of methane, nitrous oxide, three chlorofluorocarbons, methyl chloroform, chloroform, and carbon tetrachloride. This database supports analyses and monitoring related to both greenhouse gases and the Earth's ozone layer. Data from 1978 through September 1999 are now available for Cape Grim, Tasmania; Point Matatula, American Samoa; Ragged Point, Barbados; Mace Head, Ireland; and Trinidad Head, California. Stations also previously existed at Cape Meares, Oregon, and Adrigole, Ireland. All Atmospheric Lifetime Experiment (ALE) and Global Atmospheric Gases Experiment (GAGE) data have been recalculated according to the current Advanced Global Atmospheric Gases Experiment (AGAGE) calibration standards, thus creating a unified ALE/GAGE/AGAGE data set based upon the same standards. The AGAGE database has been completely re-computed to introduce a new and improved pollution analysis scheme.

\subsubsection{Climate}

\section{Annual and Seasonal Global Temperature Deviations in the Troposphere and Low Stratosphere, 1958-1998}

Contributed by Angell, J. K., Air Resources Laboratory, National Oceanic and Atmospheric Administration, Silver Springs, Maryland

Prepared by Dale P. Kaiser and Sonja B. Jones, CDIAC

NDP-008 (updated: October 1999)

(http://cdiac.esd.ornl.gov/ndps/ndp008.htm)

Surface temperatures and thickness-derived temperatures from a global network of 63 radiosonde stations were used to estimate annual and seasonal temperature deviations (calculated relative to a 1958-1977 reference period mean) over the globe and several zonal regions from 1958 through 1998.

Most of the values are column-mean temperatures obtained from the differences in height between constant-pressure surfaces at individual radiosonde stations. The pressure-height data before 1980 were obtained from published values in Monthly Climatic Data for the World. Between 1980 and 1990, Angell used data from both the Climatic Data for the World and the Global Telecommunications System (GTS) Network received at the National Meteorological Center. Between 1990 and 1995, the data were obtained only from GTS, and since 1995, the data have been obtained from the National Center for Atmospheric Research files. These temperature deviations may be used to analyze long-term temperature trends for a layer of the 
atmosphere (i.e., surface, troposphere, tropopause, and low stratosphere), a region (i.e., polar, temperate, subtropical, and equatorial), a hemisphere, or the globe.

\subsubsection{Carbon Cycle}

Global, Regional, and National $\mathrm{CO}_{2}$ Emission Estimates from Fossil Fuel Burning, Cement Production, and Gas Flaring: 1751-1997

Compiled by Marland, G., and T. A. Boden, CDIAC; and R. J. Andres, Institute of Northern Engineering, School of Engineering, University of Alaska-Fairbanks, Fairbanks, Alaska

Prepared by Thomas A. Boden, CDIAC

NDP-030 (updated: August 2000)

(http://cdiac.esd.ornl.gov/ndps/ndp030.htm)

Global, regional, and national annual estimates of $\mathrm{CO}_{2}$ emissions from fossil fuel burning, cement production, and gas flaring have been calculated through 1997, some as far back as 1751. These estimates, derived primarily from energy statistics published by the United Nations (UN), were calculated using the methods of Marland and Rotty (1984). Cement production estimates from the U.S. Department of Interior's Bureau of Mines were used to estimate $\mathrm{CO}_{2}$ emitted during cement production. Emissions from gas flaring were derived primarily from UN data but were supplemented with data from DOE's Energy Information Administration (Rotty 1974) and with a few national estimates provided by G. Marland.

\subsection{Trends Online}

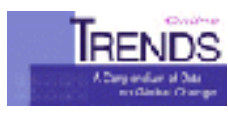

\subsubsection{Atmospheric Trace Gas Concentrations}

\subsubsection{Carbon dioxide and carbon isotopes}

\section{Atmospheric $\mathrm{CO}_{2}$ Records from Sites in the SIO Air Sampling Network}

Contributed by Keeling, C. D., and T. P. Whorf, Scripps Institution of Oceanography (SIO), University of California, San Diego, California

Prepared by Thomas A. Boden, CDIAC

(updated: September 2000)

(http://cdiac.esd.ornl.gov/trends/co2/sio-keel.htm) 
Ambient atmospheric $\mathrm{CO}_{2}$ data from the Mauna Loa Observatory, Mauna Loa, Hawaii; Barrow, Alaska; Cape Matatula, American Samoa; and the South Pole have been updated though 1999. All digital data, figures, and documentation are available in Trends Online.

The ambient atmospheric $\mathrm{CO}_{2}$ measurements taken at the Mauna Loa Observatory since 1958 constitute the longest continuous record of atmospheric $\mathrm{CO}_{2}$ concentrations available in the world. The Mauna Loa site is considered one of the most favorable locations for measuring undisturbed air because the possible local influences of vegetation or human activities on atmospheric $\mathrm{CO}_{2}$ concentrations are minimal and any influences from volcanic vents may be excluded from the records. The methods and equipment used to obtain these measurements have remained essentially unchanged during the 40 -plus years of the monitoring program.

Between 1959 and 1999, the Mauna Loa record shows a 16.6\% rise in the mean annual concentration, increasing from 315.83 parts per million by volume (ppmv) of dry air to 368.37 ppmv. A 2.9-ppmv increase in mean annual concentration from 1997 to 1998 represents the largest single yearly jump since the Mauna Loa record began in 1958; the 1998-1999 increase in mean annual concentration was $1.67 \mathrm{ppmv}$. Since 1974, the annual average $\mathrm{CO}_{2}$ concentration at Barrow has risen from 332.60 ppmv to 369.68 ppmv in 1999 (constituting an annual increase of $1.4 \mathrm{ppmv}$ ). The Barrow record is screened to be indicative of maritime air masses and shows the large seasonal amplitude typical for high latitude northern sites. At Cape Matatula, the annual concentration of $\mathrm{CO}_{2}$ rose from 340.43 ppmv in 1982 to $367.02 \mathrm{ppmv}$ in 1999 (displaying an average annual growth rate of $\sim 1.5 \mathrm{ppmv}$ ). At the South Pole, the average annual $\mathrm{CO}_{2}$ concentration rose from 327.45 ppmv in 1973 to 365.69 ppmv in 1999 (constituting an annual increase of $>1.4 \mathrm{ppmv}$ ).

\section{Atmospheric $\mathrm{CO}_{2}$ Records from Sites in the NOAA/CMDL Continuous Monitoring Network}

Contributed by Thoning, K.W., and P. P. Tans, NOAA, Climate Monitoring and Diagnostics Laboratory, Boulder, Colorado

Prepared by Thomas A. Boden, CDIAC

(updated: February 2000)

(http://cdiac.esd.ornl.gov/trends/co2/nocm.htm)

The atmospheric $\mathrm{CO}_{2}$ records from four sites in the National Oceanic and Atmospheric Administration/Climate Monitoring and Diagnostics Laboratory (NOAA/CMDL) continuous monitoring network have been updated to include data through 1998. Based on this continuous $\mathrm{CO}_{2}$ record, since 1974 the annual average atmospheric $\mathrm{CO}_{2}$ concentration at Point Barrow, Alaska, has risen from 333.94 ppmv to 367.41 ppmv in 1998; at Mauna Loa, Hawaii, from 332.04 in 1976 to 366.49 ppmv in 1998; at Cape Matatula, American Samoa, from 331.45 in 1976 to 360.92 ppmv in 1996; and at the South Pole Observatory, from 329.33 in 1975 to $363.61 \mathrm{ppmv}$ in 1998. These observations are considered representative of "clean" concentrations in the 
well-mixed troposphere, free from such confounding influences as vegetation or urban and industrial pollution. They quantify the increasing atmospheric concentrations of this most important greenhouse gas resulting from fossil-fuel combustion, land-use change, and cement production.

\subsubsection{Greenhouse Gas Emissions}

\subsubsection{Carbon dioxide emissions from fossil-fuel $\mathrm{CO}_{2}$ consumption}

\section{Global, Regional, and National Fossil-Fuel $\mathrm{CO}_{2}$ Emissions}

Compiled by Marland, G., T. A. Boden, CDIAC; and R. J. Andrews, University of North Dakota

Prepared by Thomas A. Boden, CDIAC

(updated: August 2000)

(http://cdiac.esd.ornl.gov/trends/emis/em_cont.htm)

CDIAC's estimates of global, regional, and national $\mathrm{CO}_{2}$ emissions from fossil-fuel combustion and cement production extend from 1751-1997. The 1997 global $\mathrm{CO}_{2}$ emissions estimate of 6601 million metric tons of carbon is the highest fossil-fuel emission estimate ever. The 1997 estimate represents a $1.3 \%$ increase over 1996, continuing a trend of modest growth since a 1991-1993 decline in global $\mathrm{CO}_{2}$ emissions. The Trends Online format provides a concise summary of the methodology, time-series graphics, and tabular data in an easily downloadable format. Special listings are also provided for the top 20 emitting countries and for countries ranked by total and per capita emissions.

\subsubsection{Carbon flux from land-cover change}

\section{Carbon Flux to the Atmosphere from Land-use Changes}

Contributed by Houghton, R. A. and J. L. Hackler, The Woods Hole Research Center, Woods Hole, Massachusetts

Prepared by Robert M. Cushman, CDIAC

(published: September 2000)

(http://cdiac.esd.ornl.gov/trends/landuse/houghton/houghton.html)

This inaugural dataset in the Carbon Flux from Land-Cover Change section, "Carbon Flux to the Atmosphere from Land-Use Changes," provides annual estimates, from 1850 through 1990, of net fluxes caused by deliberate changes in land use (e.g., clearing of forests for agriculture, 
harvest of wood for fuel or timber) in nine regions of the world. The estimated global total net flux of carbon from changes in land use increased from nearly $400 \mathrm{Tg} C$ ( 1 teragram $=10^{12}$ grams) in 1850 to $2200 \mathrm{Tg} \mathrm{C}$ or $2.2 \mathrm{Pg} \mathrm{C}$ ( 1 petagram $=1,000 \mathrm{Tg}=10^{15}$ grams) in 1989 and then decreased slightly to $2100 \mathrm{Tg} \mathrm{C}$ or $2.1 \mathrm{Pg} \mathrm{C}$ in 1990 . The global net flux during the period 1850-1990 was $120 \mathrm{Pg} \mathrm{C}$. During this period, the greatest regional flux was from South and Southeast Asia ( $39 \mathrm{Pg} \mathrm{C}$ ), while the smallest regional flux was from North Africa and the Middle East ( $3 \mathrm{Pg} \mathrm{C}$ ). For the year 1990, the global total net flux was estimated to be $2.1 \mathrm{Pg}$ carbon. For comparison, the estimated 1990 carbon flux to the atmosphere from fossil-fuel combustion and cement production has been estimated at $6.1 \mathrm{Pg}$ carbon (http://cdiac.esd.ornl.gov/ trends/emis/tre_glob.htm). Interestingly, North America was actually a carbon SINK from the 1960s until the mid-1980s, and Europe represented a sink throughout the 1980s.

\subsubsection{Climate}

\subsubsection{Temperature}

\section{Historical Isotopic Temperature Record from the Vostok Ice Core}

Contributed by Petit, J. R., D. Raynaud, and C. Lorius, Laboratoire de Glaciogie et Gééophysique de l'Environnement, CNRS, Saint Martin d'Hèères Cedex, France

Prepared by Linda Allison, CDIAC

(published: January 2000)

(http://cdiac.esd.ornl.gov/trends/temp/vostok/jouz_tem.htm)

Because isotopic fractions of oxygen-18 $\left({ }^{18} \mathrm{O}\right)$ and deuterium $\left({ }^{2} \mathrm{H}\right.$ or $\left.\mathrm{D}\right)$ in snowfall are temperature-dependent and a strong spatial correlation exists between the annual mean temperature and the mean isotopic ratio $\left({ }^{18} \mathrm{O} /{ }^{16} \mathrm{O}\right.$ or $\left.\mathrm{D}\right)$ of precipitation, it is possible to derive ice-core climate records from the isotopic composition. This record was based on the 3623-m ice core drilled at the Vostok station in central east Antarctica, the deepest ice core ever recovered. The resulting core allowed the ice core record of climate properties at Vostok to be extended to 420,000 years BP.

From the extended Vostok record, Petit et al. concluded that present-day atmospheric burdens of carbon dioxide and methane seem to have been unprecedented during the past 420,000 years. Although the third and fourth climate cycles evident in the Vostok record are of shorter duration than the first two cycles, all four climate cycles show a similar sequence of a warm interglacial, followed by colder glacial events, and ending with a rapid return to an interglacial period. Minimum temperatures are within $1 \mathrm{EC}$ for the four climate cycles. The overall amplitude of the glacial-interglacial temperature change is $\sim 8 \mathrm{EC}$ for the temperature above the inversion level and $\sim 12 \mathrm{EC}$ for surface temperatures. 


\section{Global and Hemispheric Temperature Anomalies-Land and Marine Instrumental} Records

Contributed by Jones, P. D., T. J. Osborn, and K. R. Briffa, University of East Anglia, Norwich, United Kingdom, and D. E. Parker, Hadley Centre for Climate Prediction and Research, Bracknell, United Kingdom

Prepared by Dale P. Kaiser, CDIAC

(updated: June 2000)

(http://cdiac.esd.ornl.gov/trends/temp/jonescru/jones.htm)

The temperature records in this database have been updated through 1999. These data were corrected for nonclimatic factors, such as location shifts and/or instrument changes. The resulting data set has been used extensively in various Intergovernmental Panel on Climate Change (IPCC) reports, and the global-mean temperature changes evident in the record have been interpreted in terms of anthropogenic forcing influences and natural variability. Trends in annual mean temperature anomalies for the globe show relatively stable temperatures from the beginning of the record (1856) through about 1910, with relatively rapid and steady warming through the early 1940 s, followed by another period of relatively stable temperatures through the mid-1970s, then another rapid rise similar to that earlier in the century. The year 1998 is the warmest year of the record; 1999 is the fifth warmest. The seven warmest years of the global record have all occurred since 1990. These are, in descending order, 1998, 1997, 1995, 1990, 1999, 1991, and 1994.

\section{Global, Hemispheric, and Zonal Temperature Deviations Derived from Radiosonde Records}

Contributed by Angell, J. K., Air Resources Laboratory, National Oceanic and Atmospheric Administration, Silver Springs, Maryland, USA

Prepared by Sonja B. Jones and Dale P. Kaiser, CDIAC

(updated: October 1999)

(http://cdiac.esd.ornl.gov/trends/temp/angell/angell.htm)

Data from a global network of 63 radiosonde stations were used to estimate global, hemispheric, and zonal annual and seasonal temperature variations from 1958 through 1998. These estimates are categorized vertically (for the near-surface, troposphere, tropopause, low stratosphere, and the surface up to $100 \mathrm{mb}$ ) and horizontally (for the globe, the Northern and Southern Hemispheres, and the North and South Polar, North and South Temperate, North and South Subtropical, Tropical, and Equatorial latitudinal zones). 
The data were obtained from values published in Monthly Climatic Data for the World and Climatic Data for the World, from the Global Telecommunications System (GTS) Network, and from National Center for Atmospheric Research files. Based on this network, Angell reported that during 1958-1998 the global, near-surface air temperature warmed by $0.14 \mathrm{EC} /$ decade and the troposphere layer warmed by $0.10 \mathrm{EC} / \mathrm{decade}$. The tropopause cooled outside the tropics but warmed slightly in the tropics. The low-stratospheric layer cooled by about $0.4 \mathrm{EC} / \mathrm{dec}$ ade in the tropics and extra tropics. At both the surface and in the troposphere, 1998 was the warmest year of the 41-year record, but when the influence of the powerful El Niño of $1997-1998$ on these temperatures is taken into account, 1990 remains the warmest year of the record.

\subsection{Newsletters, Reports, and Additional Online Publications}

CDIAC Communications. Issue Number 27, Summer 2000

Edited by Sonja Jones and Karen Gibson, CDIAC

(http://cdiac.esd.ornl.gov/newsletr/summer00/ccs00.htm)

CDIAC published the Summer 2000 issue (\#27) of CDIAC's newsletter "Communications". This issue featured a lead story on "Monitoring and Verifying Changes of Organic Carbon in Soil" and described global change databases and other publications released by CDIAC.

\section{Catalog of Databases and Reports}

Compiled by Marvel Burtis, CDIAC

(ORNL/CDIAC-34)

(http://cdiac.esd.ornl.gov/epubs/catalog/index.htm)

CDIAC's catalog is a compilation of the entire list of DOE-sponsored research reports, CDIAC reports, NDPs, and databases distributed by CDIAC.

\section{CDIAC Publications, Presentations, and Awards}

Prepared by Robert M. Cushman, CDIAC

ORNL/CDIAC-101 (updated: January 2000)

(http://cdiac.esd.ornl.gov/epubs/cdiac/cdiac101/cdiac101.htm)

This bibliography (available online only) lists CDIAC's journal articles, book and proceedings chapters, numeric data packages and online databases, other ORNL and DOE reports 
published by CDIAC, presentations by CDIAC staff, and awards presented to CDIAC since its establishment in 1982.

\section{Fiscal Year 1999 Annual Report}

Contributed by Cushman, R. M., Thomas A. Boden, Les A. Hook, Sonja B. Jones, Dale P. Kaiser, and Tommy Nelson, CDIAC

Prepared by Marvel D. Burtis, CDIAC

ORNL/CDIAC-126 (published: March 2000)

(http://cdiac.esd.ornl.gov/epubs/cdiac/cdiac126/annualrp99.htm)

The report documents highlights from the fiscal year (new data products and other publications); provides information on CDIAC Focus Areas; provides statistics, such as the number of requests for global change data and information from CDIAC and citations in the published literature of data obtained from CDIAC; alerts users to new data products that CDIAC hopes to release in FY 2000; lists awards received by CDIAC and publications and presentations of its staff; and lists the many organizations with which CDIAC has collaborated to produce the data and information products it released in FY 1999.

\section{Bibliography on $\mathrm{CO}_{2}$ Effects on Vegetation and Ecosystems: 1990-1999 Literature}

Complied by Jones, M. H., and Peter S. Curtis, The Ohio State University, Columbus, Ohio

Prepared by Robert M. Cushman, CDIAC

ORNL/CDIAC-129 (revised: July 2000)

(http://cdiac.esd.ornl.gov/epubs/cdiac/cdiac129/cdiac129.html)

This database provides complete bibliographic citations (plus abstracts and keywords, when available) for more than 2,700 references published between 1990 and 1999 on the direct effects of elevated atmospheric concentrations of $\mathrm{CO}_{2}$ on vegetation, ecosystems, their components and interactions. This bibliography is an update to Direct Effects of Atmospheric $\mathrm{CO}_{2}$ Enrichment on Plants and Ecosystems: An Updated Bibliographic Data Base (ORNL/CDIAC-70), edited by Boyd R. Strain and Jennifer D. Cure, which covered literature from 1980 to 1994. This bibliography was developed to support The Ohio State University's (OSU) Carbon Dioxide MetaAnalysis Project $\left(\mathrm{CO}_{2} \mathrm{MAP}\right)$, but was designed to be useful for a wide variety of purposes related to the effects of elevated $\mathrm{CO}_{2}$ on vegetation and ecosystems.

The data base is available as a Papyrus ${ }^{\mathrm{TM}}$ (a registered trademark of Research Software Design, 2718 SW Kelly St., Suite 181, Portland, OR 97201 USA) bibliographic files. In addition, an alphabetical (by author) listing of the contents of the data base are available in WordPerfect $\circledast$ 
(a registered trademark of the Corel Corporation, 1600 Carling Ave., Ottawa, Ontario, Canada K1Z 8R7), ascii, and Adobe $\AA^{\circledR}$ Acrobat ${ }^{\circledR}$ software in pdf format. A keyword index may be used to locate specific citations of interest.

\section{Graduate Student Theses Supported by DOE's Environmental Sciences Division: FY 2000 Update}

Compiled by Cushman, R. M., CDIAC, A. Harrison, and Katie Stevens, National Institute for Global Environmental Change National Office, University of California, Davis

(updated: September 2000)

(http://cdiac.esd.ornl.gov/epubs/cdiac/cdiac130/cdiac130.htm)

This update is an addendum to the 1995 report, Graduate Student Theses Supported by DOE's Environmental Sciences Division, providing complete bibliographic citations, abstracts, and keywords for 70 doctoral and masters' theses published between 1994 and 2000, supported fully or partly by DOE's Environmental Sciences Division in the following areas: Atmospheric Chemistry; Marine Transport; Carbon, Climate, and Vegetation; Computer Hardware, Advanced Mathematics, and Model Physics (CHAMMP); Coastal Margins; and National Institute for Global Environmental Change (NIGEC). Information on the major professor, department, principal investigator, and program area is given for each abstract.

\subsection{What's Coming in FY 2001}

CDIAC is currently working on the following new and existing data and information products for FY 2001. Please note that many have already been completed.

\subsubsection{New and Updated Information Products}

\subsubsection{Land use and ecosystems}

\section{Carbon Flux to the Atmosphere from Land-use Changes 1850 to 1990}

Contributed by Houghton, R. A., and J. L. Hackler, The Woods Hole Research Center, Woods Hole, Massachusetts

Prepared by Robert M. Cushman, CDIAC

NDP-050/R1 (date completed: February 2001)

(http://cdiac.esd.ornl.gov/epubs/ndp/ndp050/ndp050.html)

This updated NDP replaces the version published by CDIAC in 1995 and includes the data corresponding to Houghton's 1999 paper "The Annual Net Flux of Carbon to the Atmosphere From Changes in Land Use 1850-1990" in the journal Tellus (volume 51B, pages 298-313). The 
database consists of annual estimates of the net flux of carbon between terrestrial ecosystems and the atmosphere resulting from deliberate changes in land cover and land use. The data are provided on a year-by-year basis for nine regions (North America, South and Central America, Europe, North Africa and the Middle East, Tropical Africa, the Former Soviet Union, China, South and Southeast Asia, and the Pacific Developed Region); global totals are also given. The global net flux during the period 1850 to 1990 was $124 \mathrm{Pg}$ of carbon. During this period, the greatest regional flux was from South and Southeast Asia (39 Pg of carbon), while the smallest regional flux was from North Africa and the Middle East (3 Pg of carbon). For the year 1990, the global total net flux was estimated to be $2.1 \mathrm{Pg}$ of carbon.

\subsubsection{Oceanographic trace gases}

Carbon Dioxide, Hydrographic, and Chemical Data Obtained During the R/V Knorr Cruises 138-3, -4, and -5 in the South Pacific Ocean (WOCE Sections P6E, P6C, and P6W, May 2 July 30, 1992)

Contributed by Johnson, K. M., Brookhaven National Laboratory, New York; M. Haines, R. M. Key, Princeton University, Princeton, New Jersey; C. Neill; B. Tilbrook, Commonwealth Scientific and Industrial Research Organisation, Australia; R. Wilke, and D. W. R. Wallace, Brookhaven National Laboratory, New York

This data documentation discusses the procedures and methods used to measure total carbon dioxide $\left(\mathrm{TCO}_{2}\right)$ and partial pressure of carbon dioxide $\left(\mathrm{pCO}_{2}\right)$ at hydrographic stations during the R/V Knorroceanographic cruises 138-3, -4 , and -5 in the South Pacific Ocean (Section P6). The work was divided into three legs designated as P6E, P6C, and P6W which correspond to cruises 138-3, -4 , and -5 , respectively. Conducted as part of the World Ocean Circulation Experiment (WOCE), the P6 section began in Valparaiso, Chile, on May 2, 1992, and ended 81 days later in Sydney, Australia, on July 30,1992. Measurements made along WOCE Section P6 included atmospheric pressure, temperature, salinity [measured by a conductivity, temperature, and depth sensor (CTD)], bottle salinity, bottle oxygen, silicate, nitrate, nitrite, phosphate, radiocarbon $\left({ }^{14} \mathrm{C}\right), \mathrm{TCO}_{2}$, and $\mathrm{pCO}_{2}$.

\subsubsection{Climate}

Annual and Seasonal Global Temperature Deviations in the Troposphere and Low Stratosphere, 1958-1999

Contributed by Angell, J. K., Air Resources Laboratory, National Oceanic and Atmospheric Administration, Silver Springs, Maryland

Prepared by Dale P. Kaiser and Sonja B. Jones, CDIAC

NDP-008 (completed: November 2000)

(http://cdiac.esd.ornl.gov/ndps/ndp008.html) 
This updated numeric data package, which provides surface temperatures and thickness-derived temperatures from a 63-station, globally distributed radiosonde network, has been used to estimate global, hemispheric, and zonal annual and seasonal temperature deviations from 1958 through 1999. Most of the temperature values used were column-mean temperatures, obtained from the differences in height (thickness) between constant-pressure surfaces at individual radiosonde stations. The data are evaluated as deviations from the mean based on the interval 1958-1977 and pertain to the surface and the following atmospheric layers: troposphere (850-300 mb), tropopause (300-100 mb), low stratosphere (100-50 and $100-30 \mathrm{mb}$ ), and from the surface up to $100 \mathrm{mb}$. Individual data sets containing the above measurements are provided for the globe, the Northern and Southern Hemispheres, and the following latitudinal zones: North Polar (60E-90EN) and South Polar (60E-90ES); North Temperate (30E-60EN) and South Temperate (30E-60ES); North Subtropical (10E-30EN) and South Subtropical (10E-30ES); Tropical (30EN-30ES); and Equatorial (10EN-10ES).

\section{A Databank of Antarctic Surface Temperature and Pressure Data}

Contributed by Jones, P. D., and P. A. Reid, Climatic Research Unit, University of East Anglia, Norwich, United Kingdom

This database will offer monthly mean surface temperature and mean sea level pressure data from twenty-nine meteorological stations within the Antarctic region. The first version of this database, compiled at the Climatic Research Unit, extended through 1988, and was originally made available by CDIAC in 1989 as NDP-032. This update to NDP-032 includes data through early 1999 for most stations (through 2000 for a few) and also includes all available mean monthly maximum and minimum temperature data. For many stations this means that more than 40 years of data are now available, enough for many of the trends associated with recent warming to be more thoroughly examined. Much of the original version of this dataset was obtained from the World Weather Records (WWR) volumes (1951-1970), Monthly Climatic Data for the World (since 1961), and several other sources. Updating the station surface data involved requesting data from countries that have weather stations on Antarctica. Of particular importance within this study are the additional data obtained from Australia, Britain, and New Zealand.

\subsubsection{Trends Online Update}

CDIAC is continually expanding Trends Online with additions and updates. Coming (or completed) in FY 2001:

! Trifluoromethyl Sulfur Pentafluoride $\left(\mathrm{SF}_{5} \mathrm{CF}_{3}\right)$ and Sulfur Hexafluoride $\left(\mathrm{SF}_{6}\right)$ from Dome Concordia (Sturges et al.) (http://cdiac.esd.ornl.gov/trends/otheratg/sturges/sturges.html)

! Atmospheric Fluoroform ( $\left.\mathrm{CHF}_{3}, \mathrm{HFC}-23\right)$ at Cape Grim, Tasmania (Oram et al.) (http://cdiac.esd.ornl.gov/trends/otheratg/oram/oram.html)

! Fossil-fuel $\mathrm{CO}_{2}$ emissions (http://cdiac.esd.ornl.gov/trends/emis/em_cont.htm) 
! Global, hemispheric, and zonal temperature deviations derived from radiosonde records (Angell) (http://cdiac.esd.ornl.gov/trends/temp/angell/angell.html)

! Trends in Total Cloud Amount Over China (Kaiser) (http://cdiac.esd.ornl.gov/trends/clouds/kaiser/kaiser98.html)

! Global and Hemispheric Temperature Anomalies-Land and Marine Instrumental Records (Jones et al.) (http://cdiac.esd.ornl.gov/trends/temp/jonescru/jones. $h$ tml)

! Atmospheric $\mathrm{CO}_{2}$ record from flask measurements at Lampedusa Island (Chamard et al.) (http://cdiac.esd.ornl.gov/trends/co2/lampis.htm)

! Atmospheric $\mathrm{CO}_{2}$ record from continuous measurements at Jubany Station, Antarctica (Ciattaglia and Rafanelli) (http://cdiac.esd.ornl.gov/trends/co2/jubany.htm)

Remember to check the "New" page on our Web site (http://cdiac.esd.ornl.gov/new/new.htm) for announcements of the latest CDIAC data and information products. 


\section{Information Services}

\subsection{FY 2000 Statistics}

Statistics calculated from FY 2000 activity CDIAC indicate that users are predominately accessing our data and information products via our Web site. While CDIAC continues to receive and respond to users via traditional methods (e.g, email, mail, fax, telephone) and users continue to access data products through direct FTP, statistics from these areas are minute in comparison to the statistics generated from CDIAC's Web activity.

! In FY 2000, CDIAC's Web site received more than 250,000 visits with users viewing greater than 1,735,000 Web pages. These numbers nearly double those of FY 1999, when users viewed 760,000 pages (then a record) during 137,000 visits.

! The average number of pages viewed per day in FY 2000 was 4,754, and the average visit to CDIAC's Web site lasted approximately 15 minutes.

! Visits to CDIAC's Web site were made from 100 different domains, ten percent more domains than in FY 1999. Of these 100 domains, 91 represented foreign countries.

! Shown below are the major keywords used to locate CDIAC data and information products via online search engines (e.g., Yahoo, AltaVista, google.com, netscape.com, msn.com, etc.):
S carbon dioxide
S greenhouse effect
S carbon
S $\mathrm{CO}_{2}$
S cdiac
S climatology
S carbon dioxide emissions
S precipitation

! Some 300 browsers were utilized in accessing CDIAC's Web site. Interestingly, of the total 250,000 visits to our site, Microsoft Internet Explorer users represented 92,073 of those visits, and Netscape Navigator users represented 91,932 visits. Slurp.so and America Online were the other top browsers used to access CDIAC data and information products.

! As might be expected, the top host accessing our site was America Online, and the top domain was U.S. Commercial. 


\subsection{FY 2000 Internet Requests}

\section{Requests Total Nearly 140,000 in FY 2000}

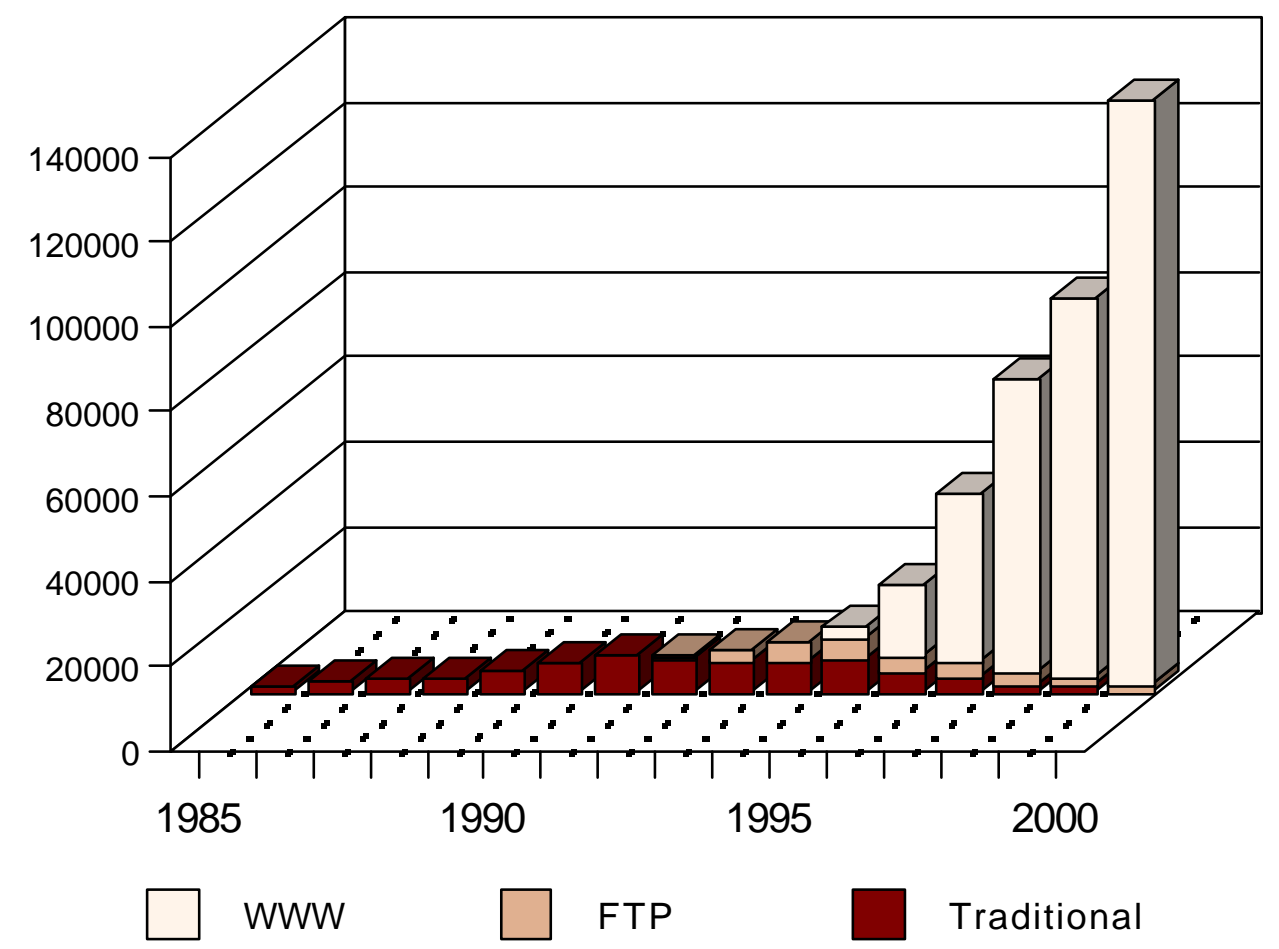

\section{CDIAC Users Worldwide}

! Educators (teachers, professors)

! Students (elementary, high school, college graduate and undergraduate)

! General Public (interested citizens, special interest groups)

! Specialists (scientists, engineers, business and industry)

! Government (legislative assistants, policymakers, agencies)

! Media (radio, television, newspapers) 


\section{Foreign Countries Visiting CDIAC's Web Site}

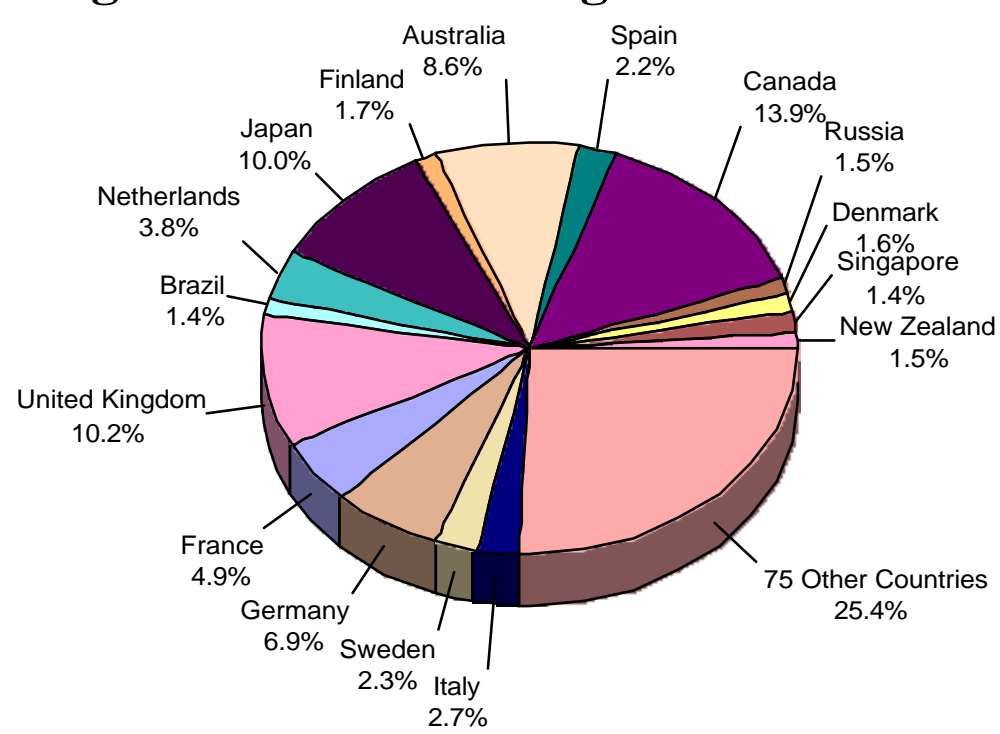

\section{Web Visits by User Domain}

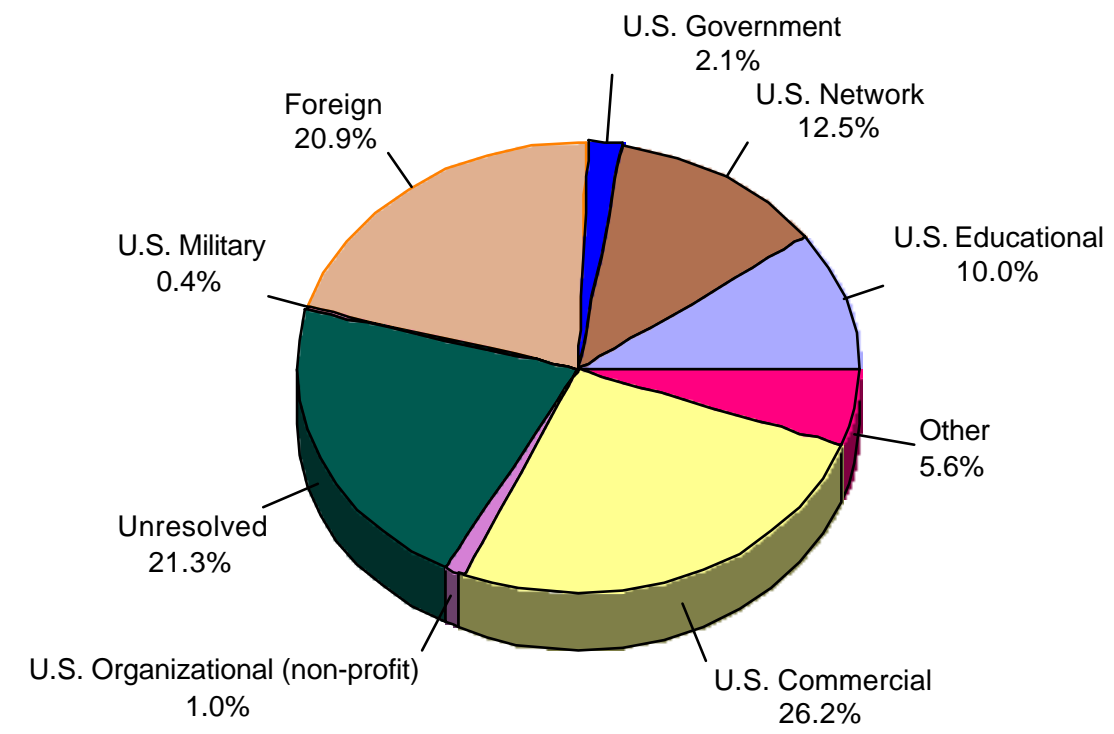




\section{Comparison of FY 2000 and FY 1999 Views/Visits}

Y2000
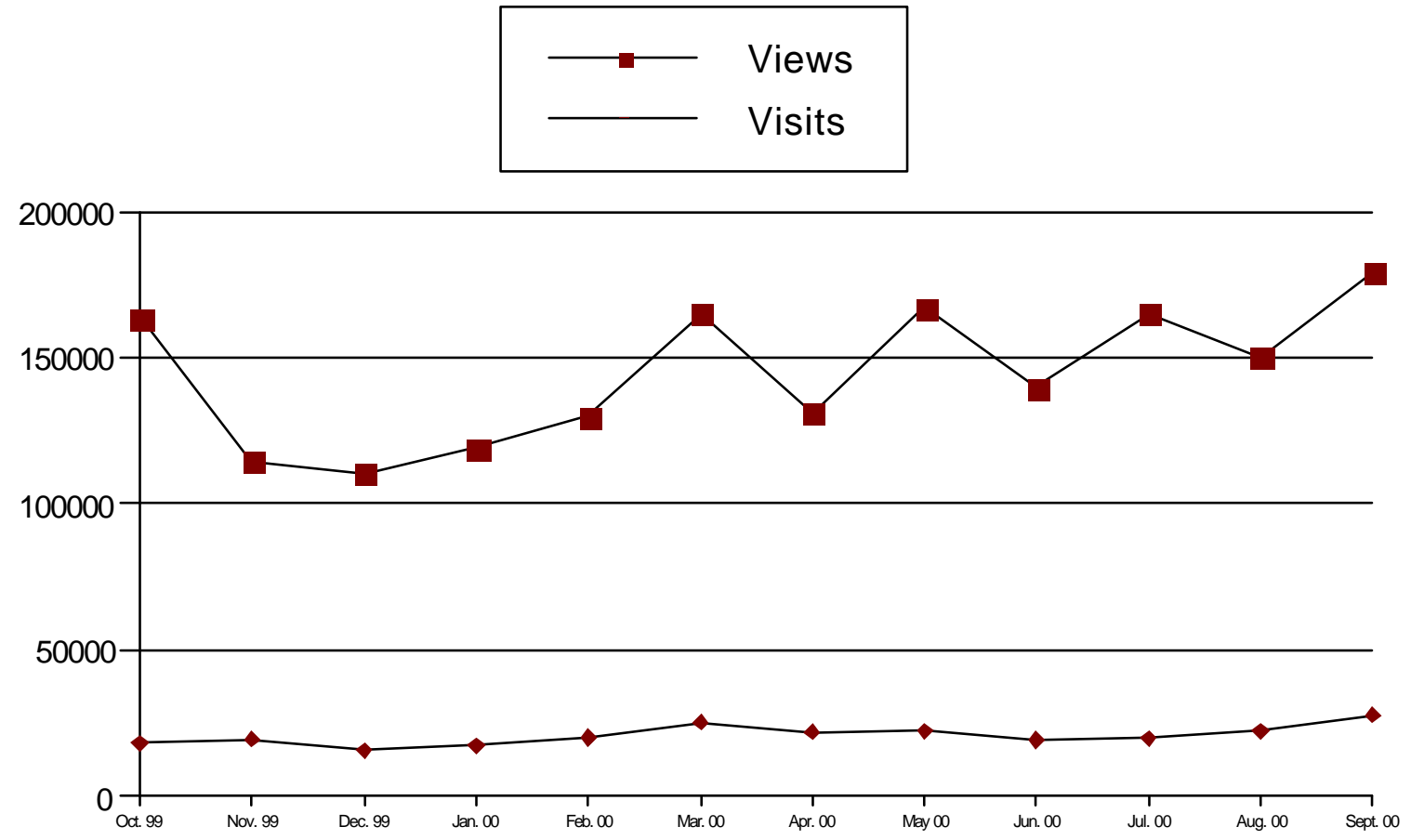

FY1999

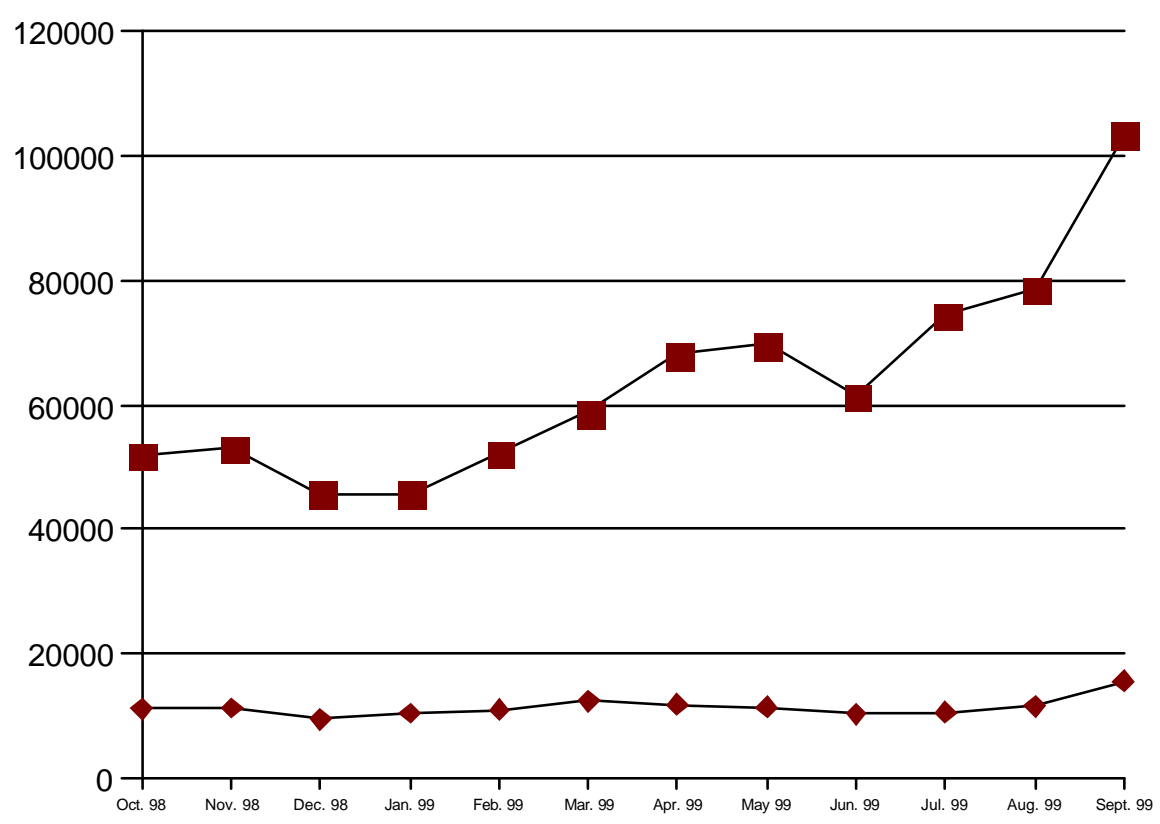




\section{Computer Systems Development}

CDIAC's Computer Systems continues to search for ways to improve our operation and increase efficiency. Over the past few years, we have achieved great success by making our products available via our Web site and FTP server. Electronic distribution not only cuts publication and distribution costs but also allows us to deliver more timely information to a rapidly expanding audience. The response to easily accessible electronic publications and data has been outstanding. This response by our user community is exactly what we hoped to achieve. However, to keep pace with the proliferation of data and increasing global interest in those data, we must continue to anticipate the impact of emerging information technologies and position ourselves to apply those technologies to meet the needs of our audience.

\subsection{Infrastructure Improvements}

\subsubsection{Network Upgrade}

The growth in electronic distribution, projections for continued growth in this area, the trend to larger data sets, and the resulting need to interactively format and extract data subsets once again established a clear need for improved tools to accomplish these tasks. Previously, we undertook wholesale hardware upgrades by implementing a new 4-processor Sun® Enterprise 450 server, doubling our RAID (redundant array of independent disks) storage capacity, and implementing an automated digital linear tape (DLT) storage library. We completed these infrastructure improvements in FY 2000 by upgrading our communications network. This upgrade moved us from fixed transmission rates to a fiber-based, switched system. This upgrade resulted in a tenfold increase of our network throughput and much more efficient routing of local network traffic.

\subsubsection{New Metadata Standard}

Having successfully completed upgrades to our central server hardware, we turned our attention to improving our data/software infrastructure. There are many new, rapidly developing information management tools designed to help users accurately locate pertinent data while eliminating extraneous information. These tools, typically XML (eXtensible Markup Language) -based, require complete and accurate metadata to be useful. To take full advantage of these tools at CDIAC, we created and implemented a new metadata standard. While being legible and readily understandable by humans, our new standard is compliant with the Federal Geographic Data Committee (FGDC) metadata content standard and will work well with evolving XML-based tools. We inventoried and reviewed our existing metadata holdings and then set about the tedious process of expanding the metadata associated with each of our products. This process ensured that current metadata records were comprehensive, complete, and in accordance with the new standard. This process was successfully completed, with new metadata (.met) files created for each CDIAC product.

\subsubsection{New Analysis Software}

We also purchased and installed SAS/Insight software on our central server. SAS/Insight compliments the other components of the SAS System at CDIAC by providing an interactive tool for exploring and analyzing data. It allows CDIAC staff to quickly examine univariate distributions, visualize multivariate data, and evaluate models through an extensive suite of statistical techniques 
and graphical representations. These preliminary analyses serve as a discovery tool to guide staff in the application of statistical analysis methodologies, which are part of CDIAC's extensive quality assurance process.

\subsubsection{Desktop Development/Analysis Platform}

Finally, we evaluated several alternatives for replacing our aged desktop hardware. After considerable testing, we arrived at a cost-effective combination that provides tremendous flexibility. The winning combination consists of the Linux operating system, Intel/AMD-based hardware $\AA_{\text {, }}$ VMware $\AA$, and Windows $2000 \AA$. VMware $\AA$ is a thin software layer that sits between the hardware architecture and the operating system, creating a virtual machine and managing all hardware resources. This software allows us to run any version of Microsoft Windows $\AA$, from Windows $3.1{ }^{\circledR}$ to Windows $2000 \AA$, as a guest operating system. This configuration affords us the features and security of a UNIX®-based operating system while allowing us to utilize Windows-based tools and test our products in various Windows $\AA$ environments. One attractive feature Vmware ${ }^{\circledR}$ provides is the ability to move in and out of applications across the different operating systems without rebooting. Having completed our testing, and based on the positive results, we will begin migrating to this desktop configuration in FY 2001.

\subsection{Carbon Sequestration Web Server}

At the request of DOE program management, we configured a Sun workstation, hardware and software, to function as the server for the Carbon Sequestration Web site. This Web server is still under our direction, and has received over 50,000 visits from countries around the world.

\subsection{Y2K Preparation and Outcome}

Our diligent application of DOE and ORNL guidelines in preparation for the year 2000 prepared us well for the new millennium. We experienced no computer system problems resulting from the millennium changeover.

\subsection{Computer Systems Maintenance and Updates}

We also spent a considerable amount of time performing necessary routine functions in support of the CDIAC Computing System Network. These tasks included backing up nightly, upgrading/replacing disk drives, creating new file systems, installing/upgrading application software and operating system enhancements, restoring user-deleted files, installing/replacing uninterruptible power supply (UPS), responding to a wide variety of CDIAC staff calls for help, producing Web statistics, making wholesale Web changes (e.g., area code), providing Web design direction, and maintaining general Web development area.

\subsection{Plans for FY 2001}

Based on system improvements implemented in FY 1999 and FY 2000, we are well-positioned to take full advantage of evolving computing and information management technologies. We have plans to implement several new information management tools under development at ORNL. We 
are excited by what these tools will offer our user community and look forward to a productive year in FY 2001.

We will replace our existing desktop systems by implementing the new desktop development/analysis platform described in 5.1. This combination consists of the Linux operating system $\AA$, Intel/AMD-based hardware $\AA$, VMware $\AA$, and Windows $2000 \AA$.

We will work with DAAC staff to develop a CDIAC application of their ORNL Metadata Editor (OME). The OME will expedite metadata generation by providing a dynamic interface for the input and modification of metadata. The OME will automatically generate .met files based on the CDIAC standard and .xml files based on the XML standard. These metadata files will make CDIAC data much more visible through internet indexing services and will improve the accuracy of those services.

We will implement a CDIAC version of Mercury. Mercury, developed at ORNL, is a data search and retrieval system that utilizes metadata to perform very accurate searches. Mercury will provide our users with sophisticated data search tools, including browse trees and dynamic pick lists. In addition to these tools, the CDIAC version of Mercury will provide tools to perform spatial and temporal data searches. Mercury offers but one example of the benefits to be derived from implementation of CDIAC's new metadata standard. 


\section{CDIAC Presentations, Publications, and Awards}

\subsection{Presentations}

! Kaiser, D. P. Decreasing Cloudiness Over China: An Updated Analysis Examining Additional Variables. 80th Annual Meeting of the American Meteorological Society. Long Beach, California, January 2000.

! Kozyr, A., J. Bullister, R. Feely, M. Lamb, C. Sabine, R. Key, F. Millero, T.-H. Peng, and R. Wanninkhof. Dissolved Inorganic Carbon Crossover Points in the Pacific Ocean. 2000 Oceans Sciences Meeting, San Antonio, Texas, January 2000.

! Cushman, R., A. Kozyr, and F. Hoffman. CDIAC: Providing Global-Change Data and Information. 2000 Oceans Sciences Meeting, San Antonio, Texas, January 2000.

! Kozyr, A., and T. Boden. Data Management Provided by the Carbon Dioxide Information Analysis Center for the U.S. Department of Energy $\mathrm{CO}_{2}$ Ocean Survey During WOCE/JGOFS Cruises. International Symposium on Carbon Cycle in the North Pacific, Nagoya, Japan, February 2000.

! Hook, L. NARSTO Quality Systems and Data Management Activities. Annual Meeting of the NARSTO Executive Assembly and Executive Steering Committee, Washington D.C., March 2000.

! Christensen, S. Moving Your Data to the NARSTO Data Archive. Southern Oxidants Study (SOS) Data Analysis Workshop, Research Triangle Park, North Carolina, March 2000.

! Hook, L. NARSTO Quality Systems and Data Management Activities. U.S. EPA Particulate Matter Supersites Program, Principal Investigators' Meeting, Research Triangle Park, North Carolina, March 2000.

! Christensen, S. Moving Supersites Data to the NARSTO Permanent Data Archive. U.S. EPA Particulate Matter Supersites Program, Principal Investigators Meeting, Research Triangle Park, North Carolina, March 2000.

! Kozyr, A. Data Management Support Provided by the Carbon Dioxide Information Analysis Center for the JGOFS International Global Survey of $\mathrm{CO}_{2}$ in the Oceans. JGOFS Conference, Bergen, Norway, April 2000.

! Cushman, R. M. Data and Information Management for FACE. FACE 2000 Conference, Tsukuba, Japan, June 2000.

! Cushman, R. M. All The Greenhouse Gases: Where Do They All Come From? DOE Global Change Education Program End-of-Summer Workshop, Oak Ridge, Tennessee, August 2000. 
! Kozyr, A. Presentation of CDIAC's ocean carbon effort at two meetings in Japan, sponsored by PICES: the Symposium on North Pacific $\mathrm{CO}_{2}$ Data Synthesis (Tsukaba), and the session on North Pacific Meeting (Hakodate). Alex presented the new CDIAC data access, through Web maps, and described the new CDIAC - WOCE Collection that he created using the Ocean Data View Program (to be available shortly through the CDIAC Web site).

\subsection{Publications}

! Kaiser, D. P. 2000. Decreasing Cloudiness Over China: An Updated Analysis Examining Additional Variables. Geophysical Research Letters 27(15): 2193-2196.

! Lamb, M. F., C. L. Sabine, R. A. Feely, R. Wanninkhof, R. M. Key, G. C. Johnson, F. J. Millero, K. Lee, T.-H. Peng, A. Kozyr, J. L. Bullister, D. Greeley, R. H. Byrne, D. W. Chipman, A. G. Dickson, C. Goyet, P. R. Guenther, M. Ishii, K. M. Johnson, C. D. Keeling, T. Ono, K. Shitashima, B. Tilbrook, T. Takahashi, D. W. R. Wallace, Y. Watanabe, C. Winn, and C. S. Wong. 2001. Consistency and Synthesis of Pacific Ocean $\mathrm{CO}_{2}$ survey data. Deep-Sea Research (in press).

\subsection{Awards and Kudos}

! In February 2000, the CDIAC newsletter, CDIAC Communications, received merit awards in the Publications and On-Line Competitions of the Society for Technical Communications East Tennessee Chapter.

! The ORNL Computing, Information and Networking Division named Jim Simmons as the winner of Outstanding Customer Service Award for Networking and Workstation Services.

! Karen Gibson was named the recipient of the ORNL Environmental Sciences Division annual Technical Support Award. 


\section{Selected CDIAC Citations}

Data from CDIAC publications were cited in a number of journal articles, magazine articles, and newsletters. The following publications are representative of works that have been cited.

$D B-1016($ Li)

Brenkert, A. L. 2000. Contribution to the Development of Supply Curves of Non-CO $\mathrm{CO}_{2}$ Trace Gases (PNNL-13365). Pacific Northwest National Laboratory, Richland, Washington.

Doll, C. N. H., J.-P. Muller, and C. D. Elvidge. 2000. Night-time imagery as a tool for global mapping of socioeconomic parameters and greenhouse gas emissions. Ambio 29(3):157-162.

NDP-001 (Keeling and Whorf)

Betts, R. A. 2000. Offset of the potential carbon sink from boreal forestation by decreases in surface albedo. Nature 408:187-190.

NDP-017 (Olson et al.)

Brenkert, A. L. 2000. Contribution to the Development of Supply Curves of Non- $\mathrm{CO}_{2}$ Trace Gases (PNNL-13365). Pacific Northwest National Laboratory, Richland, Washington.

NDP-018 (Zinke et al.)

Cox, P. M., R. A. Betts, C. D. Jones, S. A. Spall, and I. J. Totterdell. 2000. Acceleration of global warming due to carbon-cycle feedbacks in a coupled climate model. Nature 408:184-187.

NDP-019 (Easterling et al.)

DeGaetano, A.T. 2000. A serially complete simulated observation time metadata file for U.S.

Daily Historical Climatology Network ( $\mathrm{HCN}$ ) stations. Bulletin of the American Meteorological Society 81:49-67.

NDP-026, NDP-026A, and NDP-026B (Hahn et al.)

Lazarus, S. M., S. K. Krueger, and G. G. Mace. 2000. A cloud climatology of the Southern Great Plains ARM CART. Journal of Climate 13:1762-1775.

NDP-030 (Boden et al.)

Brenkert, A. L. 2000. Contribution to the Development of Supply Curves of Non-CO $\mathrm{CO}_{2}$ Trace Gases (PNNL-13365). Pacific Northwest National Laboratory, Richland, Washington.

NDP-039 (Tao et al.)

Brown, R.D. 2000. Northern hemisphere snow cover variability and change, 1915-97. Journal of Climate 13:2339-2355.

Riches, M. R., W.-C. Wang, P. Chen, S. Tao, S. Zhou, and Y. Ding. 2000. Recent progress in the joint agreements on "global and regional climate change" studies between the United States and the People's Republic of China. Bulletin of the American Meteorological Society81:491-499.

Thomas, A. 2000. Climatic changes in yield index and soil water deficit trends in China. Agricultural and Forest Meteorology 102:71-81. 
Thomas, A. 2000. Spatial and temporal characteristics of potential evapotranspiration trends over

China. International Journal of Climatology 20:381-396.

NDP-040 (Razuvaev et al.)

Brown, R. D. 2000. Northern hemisphere snow cover variability and change, 1915-97. Journal of Climate 13:2339-2355.

NDP-042 (Hughes et al.)

DeGaetano, A.T. 2000. A serially complete simulated observation time metadata file for U.S.

Daily Historical Climatology Network (HCN) stations. Bulletin of the American Meteorological Society 81:49-67.

NDP-058 (Andres et al.)

Brenkert, A. L. 2000. Contribution to the Development of Supply Curves of Non- $\mathrm{CO}_{2}$ Trace Gases (PNNL-13365). Pacific Northwest National Laboratory, Richland, Washington.

NDP-058A (Brenkert)

Doll, C. N. H., J.-P. Muller, and C. D. Elvidge. 2000. Night-time imagery as a tool for global mapping of socioeconomic parameters and greenhouse gas emissions. Ambio 29(3):157-162.

NDP-059 (Easterling et al.)

Brown, R. D. 2000. Northern hemisphere snow cover variability and change, 1915-97. Journal of Climate 13:2339-2355.

NDP-070 (Easterling et al.)

DeGaetano, A. T. 2000. A serially complete simulated observation time metadata file for U.S.

Daily Historical Climatology Network ( $\mathrm{HCN}$ ) stations. Bulletin of the American Meteorological Society 81:49-67.

NDP-076 (Goyet et al.)

Bousquet, P., P. Peylin, P. Ciais, C. Le Quéré, P. Friedlingstein, and P. P. Tans. 2000. Regional changes in carbon dioxide fluxes of land and oceans since 1980. Science 290:1342-1346.

Trends '93 (ORNL/CDIAC-65) and Trends Online

Anonymous, 2000. Changing the climate of opinion. The Economist, 12 August, page 59.

Edwards Economic Research Inc. 2000. Middle East Economic Databook 2001. Motivate Publishing, Dubai, United Arab Emirates.

National Assessment Synthesis Team, U.S. Global Change Research Program. 2000. Climate Change Impacts on the United States (Overview). Cambridge University Press.

Stoss, F.W. 2000. The heat is on. EContent 23:36-44. 


\section{CDIAC Collaborations}

CDIAC realizes that it would not be possible to produce global-change data and information products without the generosity and cooperation of researchers at institutions throughout the United States and around the world. In this annual report, we have noted the collaborating individuals and institutions for each product. Listed below are the many institutions that have collaborated with CDIAC in the publication of the databases and other information products described in this report.

\subsection{DOE Laboratories}

! Brookhaven National Laboratory

\subsection{Other Federal Agencies}

! NOAA Air Resources Laboratory

! NOAA Atlantic Oceanographic and Meteorological Laboratory

! NOAA Climate Monitoring and Diagnostics Laboratory

! NOAA Pacific Marine Environmental Laboratory

\subsection{Universities/Research Institutions}

! Georgia Institute of Technology

! Lamont-Doherty Earth Observatory of Columbia University

! Massachusetts Institute of Technology

! Monterey Bay Aquarium Research Institute

! National Institute for Global Environmental Change (NIGEC) National Office (University of California, Davis)

! Ohio State University

! Oregon Graduate Institute of Science and Technology

! Portland State University

! Princeton University

! Rosenstiel School of Marine and Atmospheric Sciences, University of Miami

! Scripps Institution of Oceanography (SIO), University of California, San Diego

! University of California, Berkeley

! University of Hawaii

! University of Nebraska - Lincoln

! University of North Dakota

! University of South Florida

! Woods Hole Oceanographic Institution

\subsection{Foreign Collaborators}

! Arctic and Antarctic Research Institute, Russia

! Commonwealth Scientific and Industrial Research Organisation, Australia

! Hadley Centre for Climate Prediction and Research, United Kingdom

! Institute of Geography, Russia 
! Institute of Ocean Science, Canada

! Instituto Español de Oceanografía, Spain

! International Science Consultants, United Kingdom

! Laboratoire de Glaciologie et Géophysique de l'Environnement, France

! Laboratoire des Sciences du Climat et de l'Environnement, France

! University of East Anglia, United Kingdom 


\section{Acronyms and Abbreviations}

$\begin{array}{ll}\text { 3-D } & \text { three-dimensional } \\ \text { AES } & \text { Atmospheric Environment Service } \\ \text { AGAGE } & \text { Advanced Global Atmospheric Gases Experiment } \\ \text { ALE } & \text { Atmospheric Lifetime Experiment } \\ \text { AmeriFlux } & \text { Eddy Covariance Flux Network in North, Central, and South America } \\ \text { BIOME-BGC } & \text { Biome model - biogeochemical cycle } \\ \text { CARINA } & \text { CARbon dioxide In the North Atlantic ocean } \\ \text { CDIAC } & \text { Carbon Dioxide Information Analysis Center } \\ \text { CHAAMMP } & \text { Computer Hardware, Advanced Mathematics, and Model Physics } \\ \text { CMDL } & \text { Climate Monitoring and Diagnostics Laboratory } \\ \text { CMP } & \text { computer model package } \\ \text { CO }{ }_{2} & \text { carbon dioxide } \\ \text { CO } 2 \text { Map } & \text { Carbon Dioxide MetaAnalysis Project } \\ \text { CSIRO } & \text { Commonwealth Scientific and Industrial Research Organisation } \\ \text { CTD } & \text { conductivity, temperature, and depth } \\ \text { DAAC } & \text { Distributed Active Archive Center } \\ \text { DB } & \text { database } \\ \text { DIST } & \text { Data and Information Sharing Tool } \\ \text { DMHB } & \text { Data Management Handbook } \\ \text { DLT } & \text { digital linear tape } \\ \text { DOE } & \text { U.S. Department of Energy } \\ \text { EPA } & \text { U.S. Environmental Protection Agency } \\ \text { ESD } & \text { Environmental Sciences Division } \\ \text { FACE } & \text { Free-Air CO }{ }_{2} \text { Enrichment } \\ \text { FGDC } & \text { Federal Geographic Data Committee } \\ \text { FTP } & \text { File Transfer Protocol } \\ \text { FY } & \text { fiscal year } \\ \text { GAGE } & \text { Global Atmospheric Gases Experiment } \\ \text { GCDIS } & \text { Global Change Data and Information System } \\ \text { GLODAP } & \text { GLobal Ocean Data Analysis Project } \\ \text { GPP } & \text { gross primary production } \\ \text { GTS } & \text { Global Telecommunications System } \\ \text { HTML } & \text { Hypertext Markup Language } \\ \text { IPCC } & \text { Intergovernmental Panel on Climate Change } \\ \text { JGOFS } & \text { Joint Global Ocean Flux Study } \\ \text { JODC } & \text { Japan Oceanographic Data Center } \\ \text { LAI } & \text { leaf area index } \\ \text { MEDS } & \text { Marine Environmental Data Service (Canada) } \\ \text { MIT } & \text { Massachusetts Institute of Technology } \\ \text { MODIS } & \text { moderate-resolution imaging spectro-radiometer } \\ & \\ & \end{array}$




\begin{tabular}{ll} 
NARSTO & formerly North American Research Strategy for Tropospheric Ozone \\
NASA & National Aeronautics and Space Administration \\
NEP & net ecosystem production \\
NDP & numeric data product \\
NIGEC & \multicolumn{1}{c}{ National Institute for Global Environmental Change } \\
NOAA & National Oceanic and Atmospheric Administration \\
NODC & National Oceanographic Data Center \\
NPP & net primary production \\
NSF & National Science Foundation \\
NTSG & Numerical Terradynamic Simulation Group \\
OACES & Ocean-Atmosphere Carbon Exchange Study \\
OME & ORNL Metadata Editor \\
OSU & Ohio State University \\
ORNL & Oak Ridge National Laboratory \\
pCO & partial pressure carbon dioxide \\
PDA & permanent data archive \\
PDF & portable document format \\
pH & pH value \\
Pg & petagram \\
PICES & North Pacific Marine Science Organization \\
Pls & principal investigators \\
PM & particulate matter \\
PMEL & Pacific Marine Environmental Laboratory \\
ppmv & parts per million by volume \\
QSSC & Quality Systems Science Center \\
QSMP & Quality Systems Management Plan \\
QPHB & Quality Planning Handbook \\
RAID & redundant array of independent disk \\
R/V & Research Vessel \\
SF \\
5 CF \\
3 & trifluoromethyl sulphur pentafluoride \\
SF & sulphur hexafluoride \\
SIO & Scripps Institution of Oceanography \\
TALK & total alkalinity \\
TCO & total carbon dioxide \\
Tg & teragram \\
UN & United Nations \\
UPS & uninterruptible power supply \\
WDC & World Data Center \\
WHP & World Hydrographic Program \\
WOCE & World Ocean Circulation Experiment \\
WWR & World Weather Records \\
&
\end{tabular}


XML eXtensible Markup Language

Y2K Year 2000 